NBER WORKING PAPER SERIES

\title{
MONETARY RULES FOR SMALL, OPEN, EMERGING ECONOMIES
}

\author{
Douglas Laxton \\ Paolo Pesenti
}

Working Paper 9568

http://www.nber.org/papers/w9568

\author{
NATIONAL BUREAU OF ECONOMIC RESEARCH \\ 1050 Massachusetts Avenue \\ Cambridge, MA 02138 \\ March 2003
}

A preliminary draft of this paper was presented at the November 2002 Carnegie-Rochester Conference. The authors wish to thank Jaromæãr Benes, Katerina Mikokovæa, Jan Vlcek and David Vávra from the Czech National Bank for sharing data and contributing to the calibration of the model. In addition we thank Chris Erceg and Bennett McCallum for countless suggestions, and Tamim Bayoumi, Robert Flood, Benjamin Hunt, Peter Isard, Alessandro Rebucci, Kenneth Rogoff, David Rose, and seminar participants at Georgetown, LSE, Cambridge, Bank of England, Bank of Canada, Czech National Bank and ECB for many helpful remarks. Finally, we gratefully acknowledge the invaluable support of Michel Juillard and Susanna Mursula in developing the procedures used in the model simulations. The views expressed here are those of the authors, and do not necessarily reflect the position of the International Monetary Fund, the Federal Reserve Bank of New York, the Federal Reserve System, the National Bureau of Economic Research, or any other institution with which the authors are affiliated.

(C2003 by Douglas Laxton and Paolo Pesenti. All rights reserved. Short sections of text not to exceed two paragraphs, may be quoted without explicit permission provided that full credit including Onotice, is given to the source. 
Monetary Rules for small, open, emerging economies

Douglas Laxton and Paolo Pesenti

NBER Working Paper No. 9568

March 2003

JEL No. C51, E31, E52

\section{$\underline{\text { ABSTRACT }}$}

This paper develops a variant of the IMF's Global Economic Model (GEM) suitable to analyze macroeconomic dynamics in open economies, and uses it to assess the effectiveness of Taylor rules and Inflation-Forecast-Based (IFB) rules in stabilizing variability in output and inflation. Our findings suggest that a simple IFB rule that does not rely upon any direct estimates of the equilibrium real interest rate and places a relatively high weight on the inflation forecast may perform better in small open economies than conventional Taylor rules.

Douglas Laxton

Economic Modeling Division

International Monetary Fund

700 19th St., NW,

Washington DC 20431

dlaxton@imf.org
Paolo Pesenti

International Research

Federal Reserve Bank of New York

33 Liberty St.

New York NY 10045

and NBER

paolo.pesenti@ny.frb.org 


\section{Introduction}

Generations of policymakers have long emphasized an "impossible trinity" of policy objectives. Attempts to simultaneously maintain fixed exchange rates, perfect capital mobility, and independent monetary policy are bound to end either with a whimper or a bang. Over the 1990s, the intellectual underpinnings of the monetary frameworks adopted by central banks around the world have assigned increasing emphasis to a rather different trinity, one that is "both feasible and desirable" in the words of John Taylor (2000): this is the trinity of flexible exchange rates, an inflation target, and a monetary policy rule.

The idea that policy rules originally designed to fit the specific economic and institutional features of large and relatively closed economies may be successfully imported by small, trade-dependent countries is nowadays taken for granted. The key open question is what kind of modifications are needed to fit the complex reality of monetary policymaking in economies with less developed financial markets, more vulnerability to external sources of uncertainty, strong movements in productivity and relative prices, and destabilizing exposure to volatile capital flows.

With respect to Taylor-style interest rate rules, a frequently asked question is whether the size of the response of the instrument to inflation and output gap changes systematically with the degree of openness and the size of the country. Another recurrent theme in the literature is what role, if any, should be played by interest rate inertia. ${ }^{1}$ Finally, a controversial point concerns the desirability of exchange rate targets in monetary rules. ${ }^{2}$

This paper contributes to this debate in a number of respects. First, we set up a stochastic dynamic general equilibrium model (SDGE) of sufficient complexity to provide a satisfac-

\footnotetext{
${ }^{1}$ See e.g. Woodford (1999).

${ }^{2}$ As the focus of the paper is on the "feasible and desirable" trinity mentioned above, we abstract from the issues underlying the choice of a fixed versus flexible exchange rate regime. For a recent analysis of these issues in the context of a similar theoretical apparatus see Ghironi and Rebucci (2002) and its references.
} 
tory representation of trade and macroeconomic interdependencies between a large industrialized country and a small open economy. Next, we calibrate the model with particular attention to its ability to simulate realistic dynamic responses of relevant macroeconomic variables to a variety of shocks. Specifically, we show that the model is able to replicate closely the empirical properties of the monetary transmission mechanism, as estimated by central banks using institution-specific tools for policy evaluation. Finally, we compare the performance of alternative interest rate rules - Generalized Taylor rules versus Inflation-Forecast-Based ones — in stabilizing variability in inflation and output across the two economies of the model.

A few caveats should be immediately emphasized. The main focus of our contribution is to examine and contrast the implications of alternative monetary rules in economies that differ substantially in their size and degree of openness. From this vantage point, our analysis is broadly applicable to small, open economies regardless of their degree of industrialization and development. The specific reference to emerging economies is perhaps more controversial. Needless to say, the term "emerging" market applies to a highly heterogeneous array of institutional and economic realities, and any unqualified search for common policy prescriptions has a very good chance of being dismissed as quixotic from its very onset. In fact, in this paper we deliberately abstract from some considerations that would appear germane in setting monetary policy in many emerging economies, including central bank independence, potential fiscal constraints, credibility and time-consistency problems in adhering to rules, liquidity constraints on household or firm borrowing, and balance sheet effects of exchange rate fluctuations.

Nevertheless, most so-called "emerging" markets share a number of features that we believe our framework is fit to capture well. Emerging economies according to our characterization are sufficiently diversified and not exclusively dependent on exports of primary commodities and raw materials. Their securities markets are sufficiently developed to allow 
for a meaningful comparison of their macroeconomic properties with the ones observed in advanced industrialized countries. At the same time, their reliance on trade makes them more exposed to external fluctuations than their advanced counterparts. Also, they are intrinsically more vulnerable to a variety of shocks, both on the demand and the supply side, than their advanced counterparts.

To provide a specific example, in our simulation exercise we identify the large country with the Euro area and the small economy with the Czech Republic, a representative transition country in Central Europe that fits our definition of an emerging economy. ${ }^{3}$ In the light of the considerations above, by no means should our results be generalized to the vast majority of emerging markets without controlling for country-specific and institutional factors. Yet, our findings are meant to provide a benchmark for the analysis of monetary rules across heterogeneous economies, over which further research is expected to take off.

The paper is organized as follows. Section 2 introduces our two-country model. Section 3 discusses the calibration of the model to stylized facts for transition economies and the Euro area. Section 4 employs the model to investigate the potential role of Taylor and InflationForecast-Based rules for stabilizing output and inflation in both large and small economies. Finally, Section 5 presents our main conclusions and outlines directions for future work.

\footnotetext{
${ }^{3}$ Since our objective is to build a logically consistent two-country framework to study the implications of strong trade linkages between small and large economies, it is important to state at the outset that the calibration exercise is not meant to represent a complete model of either the Euro area or the Czech Republic. Because the calibration only models trade flows between the Czech Republic and the Euro area, we significantly underestimate the absolute degree of openness of both economies. Also, the addition of a "rest-of-world" block to the model may be helpful to study issues such as the perspective accession of Central European countries into the European Union and their transition toward full EMU membership. For a recent analysis of institutional issues in Central Europe within a SDGE framework see Natalucci and Ravenna (2002).
} 


\section{The model}

\subsection{General structure}

The theoretical framework we adopt in our analysis is a variant of the "Global Economy Model" (GEM), the new multi-country simulation model currently under development at the Research Department of the International Monetary Fund. ${ }^{4}$ The basic structure of the model is outlined in this section and illustrated in Figure 1.

The world economy consists of two countries, Home (small) and Foreign (large). Foreign variables are indexed with a star. In each country there are households, firms, and a government.

Each household is infinitely lived. Each household consumes a single nontradable final good $(A)$. Each household is the monopolistic supplier of a differentiated labor input $(\ell)$ to all domestic firms. Wage contracts are subject to adjustment costs (nominal wage rigidities). Households own domestic firms, non-reproducible resources (land $L$ ), and the domestic capital stock $(K)$, which they rent to domestic firms. The markets for land and capital are competitive. Capital accumulation is subject to adjustment costs. Labor, capital and land are immobile internationally. Households trade a short-term nominal bond, denominated in Foreign currency, and issued in zero net supply worldwide. There are intermediation costs for Home households entering the international bond market. No other asset is traded internationally.

Firms produce the final good, a continuum of differentiated nontradable intermediate

\footnotetext{
${ }^{4}$ GEM provides an extension of the stylized models considered in the "New Open-Economy Macroeconomics" theoretical literature such as Obstfeld and Rogoff (1995, 2000), Corsetti and Pesenti (2001a,b), Bacchetta and van Wincoop (2000), Tille (2001), Devereux and Engel (2001), Corsetti and Dedola (2002), Benigno and Benigno (2003), and builds on empirical SDGE open-economy applications such as Kollmann (2001), Chari, Kehoe and McGrattan (2002), Smets and Wouters (2002a), Batini, Harrison and Millard (2001), Benigno and Thoenissen (2002), Gali and Monacelli (2002). For a detailed presentation of GEM see Pesenti (2003).
} 
goods $(N)$, a continuum of differentiated tradable intermediate goods $(T)$, raw and semifinished materials $\left(T_{O}\right)$, and provide distribution and other intermediation services.

In each country, the final good is produced by perfectly competitive firms that use all intermediate goods (domestic nontradable goods, $N_{N}$, domestic tradable goods, $Q$, or imports, $M$ ) as inputs. The final good can be consumed (by domestic households, $C$, or by the government, $G_{A}$ ) or used for investment $(I)$.

Each intermediate good is produced by a single firm under conditions of monopolistic competition. Each intermediate good is produced by using domestic labor inputs, domestic capital, and a combination $(O)$ of raw and semi-finished materials, both produced domestically $\left(Q_{O}\right)$ and imported $\left(M_{0}\right)$. The nontradable intermediate goods can be purchased by the government $\left(G_{N}\right)$, used directly in the production of the nontradable final good $\left(N_{N}\right)$, or used in the distribution sector to make tradable intermediate goods available to firms producing the final good. Prices of intermediate goods are subject to adjustment costs (nominal price rigidities).

Firms in the distribution sector operate under perfect competition. They purchase tradable intermediate goods worldwide (at the producer price) and distribute them to firms producing the final good (at the consumer price). Local nontradable goods are the only input in the provision of distribution services. Firms produce tradable raw and semi-finished materials $\left(T_{O}\right)$ using labor, capital, and land. The market for raw materials is competitive. Prices of raw materials are flexible and the law of one price holds internationally.

Government spending falls exclusively on nontradable goods, both final and intermediate. Government spending is financed through tax and seigniorage revenues. The government controls the national short-term nominal interest rate. Monetary policy is specified in terms of interest rate rules. 


\subsection{Final goods production}

There is a continuum of symmetric Home firms producing the Home final good. Each firm is indexed by $x \in[0, s]$, where $0<s<1$ is a measure of country size. World size is normalized to 1 , and Foreign firms producing the Foreign final good are indexed by $x^{*} \in(s, 1]$.

Home firm $x$ 's output at time (quarter) $t$ is denoted $A_{t}(x) .{ }^{5}$ The final good is produced with the following nested CES technology:

$$
\begin{aligned}
& A_{t}(x)=\left\{\left(1-\gamma_{t}\right)^{\frac{1}{\varepsilon}} N_{N, t}(x)^{1-\frac{1}{\varepsilon}}+\gamma_{t}^{\frac{1}{\varepsilon}}\left[\nu^{\frac{1}{\varepsilon_{Q M}}} Q_{t}(x)^{1-\frac{1}{\varepsilon_{Q M}}}\right.\right. \\
& \left.\left.+(1-\nu)^{\frac{1}{\varepsilon_{Q M}}}\left[M_{t}(x)\left(1-\Gamma_{M, t}(x)\right)\right]^{1-\frac{1}{\varepsilon_{Q M}}}\right]^{\frac{\varepsilon_{Q M}}{\varepsilon_{Q M}-1}\left(1-\frac{1}{\varepsilon}\right)}\right\}^{\frac{\varepsilon}{\varepsilon-1}}
\end{aligned}
$$

Three intermediate inputs are used in the production of the final good: a basket $N_{N}$ of Home nontradable goods, a basket $Q$ of Home tradable goods, and a basket $M$ of imported Foreign tradable goods. $\varepsilon>0$ is the elasticity of substitution between tradable goods and nontradable goods, and $\varepsilon_{Q M}>0$ is the elasticity of substitution between domestic and imported inputs. The (log of) tradable goods weight $\gamma_{t}$ is subject to an auto-correlated disturbance term around a steady-state mean. ${ }^{6}$ These shocks are isomorphic to shifts in Home residents' preferences from tradable goods to nontradable goods.

To model realistic dynamics of imports volumes (such as sluggish adjustment to changes in relative prices) we assume that it is costly to change the share of the imported goods in total production. ${ }^{7}$ Imports are subject to external adjustment costs $\Gamma_{M}$, where:

$$
\Gamma_{M, t}(x) \equiv \frac{\phi_{M}}{2}\left(\frac{M_{t}(x)}{A_{t}(x)} / \frac{M_{t-1}}{A_{t-1}}-1\right)^{2}
$$

\footnotetext{
${ }^{5}$ The convention throughout the model is that variables which are not explicitly indexed (to firms or households) are expressed in per-capita (average) terms. For instance, $A_{t} \equiv(1 / s) \int_{0}^{s} A_{t}(x) d x$.

${ }^{6}$ See Table 2 for a description of the assumptions about the shocks.

${ }^{7}$ A similar specification appears e.g. in Erceg, Guerrieri and Gust (2002). For analytical simplicity we assume that a firm finds it costly to adjust its current imports/output ratio $M_{t}(x) / A_{t}(x)$ relatively to the past aggregate imports/output ratio $M_{t-1} / A_{t-1}$.
} 
Like all other adjustment costs in the model, they are treated as local services provided at zero cost: all revenue from adjustment is rebated in a lump-sum fashion to the country's residents.

The basket $N_{N}$ is a CES index of differentiated Home intermediate nontradable goods, defined over a continuum of mass $s$. Each good is produced by a single Home firm indexed by $n \in[0, s]$. Defining as $N_{N}(n, x)$ the demand by firm $x$ of an intermediate good produced by firm $n$, the basket $N_{N}(x)$ is:

$$
N_{N, t}(x)=\left[\left(\frac{1}{s}\right)^{\frac{1}{\theta}} \int_{0}^{s} N_{N, t}(n, x)^{1-\frac{1}{\theta}} d n\right]^{\frac{\theta}{\theta-1}}
$$

where $\theta>1$ denotes the elasticity of substitution among intermediate nontradable goods. Similarly, the baskets $Q$ and $M$ are CES indexes of differentiated intermediate tradable goods, respectively produced in the Home country and imported from the Foreign country. Each good is produced by a single firm. Home firms in the tradable goods sector are indexed by $h \in[0, s]$, Foreign firms in the tradable goods sector are indexed by $f \in(s, 1]$ :

$$
\begin{aligned}
& Q_{t}(x)=\left[\left(\frac{1}{s}\right)^{\frac{1}{\theta}} \int_{0}^{s} Q_{t}(h, x)^{1-\frac{1}{\theta}} d h\right]^{\frac{\theta}{\theta-1}} \\
& M_{t}(x)=\left[\left(\frac{1}{1-s}\right)^{\frac{1}{\theta^{*}}} \int_{s}^{1} M_{t}(f, x)^{1-\frac{1}{\theta^{*}}} d f\right]^{\frac{\theta^{*}}{\theta^{*}-1}} .
\end{aligned}
$$

The cost-minimization problem of Home firm $x$ can be split in two parts. First, each firm takes as given the prices of the nontradable differentiated goods $p(n)$ and minimizes $\int_{0}^{s} p_{t}(n) N_{N, t}(n, x) d n$ subject to (3). The cost-minimizing price of one unit of the nontradable basket, $P_{N}$, is equal to:

$$
P_{N, t}=\left[\left(\frac{1}{s}\right) \int_{0}^{s} p_{t}(n)^{1-\theta} d n\right]^{\frac{1}{1-\theta}}
$$

Similarly, we can derive the cost-minimizing prices of the baskets of intermediate goods $Q$ and $M$, respectively $P_{Q}$ and $P_{M}$. Next, each Home firm takes the prices of the intermediate baskets $P_{Q}, P_{M}$ and $P_{N}$ as given and minimizes $P_{Q, t} Q_{t}(x)+P_{M, t} M_{t}(x)+P_{N, t} N_{N, t}(x)$ subject to (1). As the final good sector is perfectly competitive, each firm $x$ takes the price 
of the final good $P$ as given and equates its marginal cost to the price. Foreign variables are similarly defined.

\subsection{Demand for intermediate goods and the distribution sector}

The above cost-minimization conditions imply that Home firm $x$ 's demand for input $h$ is:

$$
Q_{t}^{D}(h, x)=\left(\frac{p_{t}(h)}{P_{Q, t}}\right)^{-\theta}\left(\frac{1}{s} \int_{0}^{s} Q_{t}(h, x)^{1-\frac{1}{\theta}} d h\right)^{\frac{\theta}{\theta-1}}=\left(\frac{p_{t}(h)}{P_{Q, t}}\right)^{-\theta} \frac{Q_{t}(x)}{s}
$$

Aggregating across firms we obtain the following demand schedule for Home tradable intermediate goods $h$ :

$$
\int_{0}^{s} Q_{t}^{D}(h, x) d x=\left(\frac{p_{t}(h)}{P_{Q, t}}\right)^{-\theta} Q_{t}
$$

Similar considerations hold for $M_{t}^{D}(x)$, the demand of Foreign tradable intermediate goods $f$.

To derive the demand schedule for nontradable intermediate goods, we need to take into account the different uses of the $n$ inputs in the Home economy. First, as we have seen, nontradable goods enter directly in the production function of final goods through the basket $N_{N}$. Second, nontradable goods can be consumed by the government. Third, nontradable goods are used in the distribution sector according to the following assumptions.

Firms producing the final good cannot purchase the intermediate tradable goods directly from the producers. Instead, firms in the distribution sector purchase tradable goods both domestically and abroad and distribute them to the firms producing the final good. The distribution technology is Leontief: to make one unit of an intermediate good available to downstream producers, firms in the distribution sector require $\eta \geq 0$ units of the nontradable goods basket $N$. There are no distribution costs for nontradable goods. ${ }^{8}$

Firms in the distribution sector are perfectly competitive. Because of distribution costs, there is a wedge between producer (wholesale) and consumer (retail) prices. We denote

\footnotetext{
${ }^{8}$ The specification of the distribution sector builds on Corsetti and Dedola (2002). See also Erceg and Levin (1996) and Burstein, Neves and Rebelo (2003).
} 
with $p$ the consumer price (that is, the price paid by Home firms producing the final good) and with $\bar{p}$ the Home-currency producer price (that is, the price paid by Home firms in the distribution sector) of an intermediate good. It follows that:

$$
p_{t}(n)=\bar{p}_{t}(n), \quad p_{t}(h)=\bar{p}_{t}(h)+\eta P_{N, t}, \quad p_{t}(f)=\bar{p}_{t}(f)+\eta P_{N, t}
$$

Denoting government spending on nontradable goods by $G_{N, t}$, we can now derive the demand for Home nontradable goods $n$ as:

$$
\begin{aligned}
& \int_{0}^{s} N_{N, t}^{D}(n, x) d x+\left(\frac{p_{t}(n)}{P_{N, t}}\right)^{-\theta}\left[\eta\left(Q_{t}+M_{t}\right)+G_{N, t}\right] \\
& =\left(\frac{p_{t}(n)}{P_{N, t}}\right)^{-\theta}\left[N_{N, t}+\eta\left(Q_{t}+M_{t}\right)+G_{N, t}\right]
\end{aligned}
$$

Foreign variables are similarly characterized.

\subsection{Supply of intermediate goods}

In this section we focus on the supply of Home nontradable goods, with the understanding that the derivation of the other intermediate goods at Home and abroad follows similar steps.

Nontradable goods $n$ are produced by symmetric firms using the following CES technology:

$$
\begin{aligned}
& N_{t}^{S}(n)=Z_{N, t}\left\{\left(1-\alpha_{N}-\gamma_{N}\right)^{\frac{1}{\xi_{N}}} \ell_{t}(n)^{1-\frac{1}{\xi_{N}}}+\alpha_{N}^{\frac{1}{\xi_{N}}} K_{t}(n)^{1-\frac{1}{\xi_{N}}}\right. \\
& \left.+\gamma_{N}^{\frac{1}{\xi_{N}}}\left[O_{t}(n)\left(1-\Gamma_{O, t}(n)\right)\right]^{1-\frac{1}{\xi_{N}}}\right\}^{\frac{\xi_{N}}{\xi_{N}-1}}
\end{aligned}
$$

Firms use labor $\ell(n)$, capital $K(n)$ and a basket $O(n)$ of two tradable inputs (raw materials) produced in the Home and in the Foreign country respectively. $\xi_{N}>0$ is the constant elasticity of input substitution, and $Z_{N}$ is a stochastic process for productivity common to all producers of nontradable goods. Changes in $O(n)$ are subject to adjustment costs $\Gamma_{O}$ similar to equation (2) above. 
Differentiated labor inputs in both countries are defined over a continuum of mass equal to the country size: Home labor inputs are indexed by $j \in[0, s]$, Foreign labor inputs by $j^{*} \in(s, 1]$. Each firm $n$ uses a CES combination of labor inputs:

$$
\ell_{t}(n)=\left[\left(\frac{1}{s}\right)^{\frac{1}{\phi}} \int_{0}^{s} \ell(n, j)^{1-\frac{1}{\phi}} d j\right]^{\frac{\phi}{\phi-1}}
$$

where $\ell(n, j)$ is the demand of type- $j$ labor by the producer of good $n$ and $\phi>1$ is the elasticity of substitution among labor inputs.

$O(n)$ is a basket of raw materials defined as:

$$
O_{t}(n)=\left\{\nu_{N}^{\frac{1}{\varepsilon_{O N}}} Q_{O, t}(n)^{1-\frac{1}{\varepsilon_{O N}}}+\left(1-\nu_{N}\right)^{\frac{1}{\varepsilon_{O N}}}\left[M_{O, t}(n)\left(1-\Gamma_{M O, t}(n)\right)\right]^{1-\frac{1}{\varepsilon_{O N}}}\right\}^{\frac{\varepsilon_{O N N}}{\varepsilon_{O N}-1}}
$$

where $Q_{O}(n)$ denotes Home firm $n$ 's use of domestic raw materials and $M_{O}(n)$ denotes firm n's imports of raw materials from Foreign. Home and Foreign materials are combined with elasticity of substitution $\varepsilon_{O N}>0$. Once again, imports $M_{O}(n)$ are subject to adjustment $\operatorname{costs} \Gamma_{M O}(n)$.

Firms producing intermediate goods take the prices of labor inputs, capital and raw materials as given. Cost-minimization in the intermediate sector implies that the demand for labor input $j$ by firm $n$ is a function of the relative wage:

$$
\ell_{t}^{D}(n, j)=\left(\frac{1}{s}\right)\left(\frac{W_{t}(j)}{W_{t}}\right)^{-\phi} \ell_{t}(n)
$$

where $W(j)$ is the nominal wage paid to Home labor input $j$ and the wage index $W$ is defined as:

$$
W_{t}=\left[\left(\frac{1}{s}\right) \int_{0}^{s} W_{t}(j)^{1-\phi} d j\right]^{\frac{1}{1-\phi}}
$$

Denoting by $R$ the Home nominal rental price of capital, by $P_{Q O}$ the Home-currency price of one unit of $Q_{O}$ and by $P_{M O}$ the Home-currency price of one unit of $M_{O}$, firms in the Home nontradable goods sector minimize their costs $W_{t} \ell_{t}(n)+R_{t} K_{t}(n)+P_{Q O, t} Q_{O, t}(n)+$ $P_{M O, t} M_{O, t}(n)$ subject to (11) and (13). Cost-minimization yields expressions for $\ell_{t}^{D}(n)$, $K_{t}^{D}(n), Q_{O, t}^{D}(n), M_{O, t}^{D}(n)$ and the marginal cost $M C(n)$. 
Similar considerations hold for the production of Home tradable goods. We denote by $T^{S}(h)$ the supply of each Home-country intermediate tradable $h$. Using self-explanatory notation, we have:

$$
\begin{aligned}
& T_{t}^{S}(h)=Z_{T, t}\left\{\left(1-\alpha_{T}-\gamma_{T}\right)^{\frac{1}{\xi_{T}}} \ell_{t}(h)^{1-\frac{1}{\xi_{T}}}+\alpha_{T}^{\frac{1}{\xi_{T}}} K_{t}(h)^{1-\frac{1}{\xi_{T}}}\right. \\
& \left.+\gamma_{T}^{\frac{1}{\xi_{T}}}\left[\left(1-\Gamma_{O, t}(h)\right) O_{t}(h)\right]^{\frac{\xi_{T}-1}{\xi_{T}}}\right\}^{\frac{\xi_{T}}{\xi_{T}-1}}
\end{aligned}
$$

Following the same steps as above it is possible to derive input demands and marginal costs in the tradable goods sector. We proceed analogously in the case of Foreign nontradable goods $n^{*}$ and Foreign tradable goods $f$.

\subsection{Price setting in the intermediate sector}

Consider now profit maximization in the Home country's intermediate nontradable goods sector. Each firm $n$ takes into account the demand (10) for its product and sets the nominal price $p_{t}(n)$ by maximizing the present discounted value of real profits. There is sluggish price adjustment due to resource costs measured in terms of total profits. The adjustment cost is denoted $\Gamma_{P N, t}$ :

$$
\Gamma_{P N, t}(n) \equiv \frac{\phi_{N}}{2}\left(\frac{p_{t}(n) / p_{t-1}(n)}{P_{N, t-1} / P_{N, t-2}}-1\right)^{2}
$$

where $\phi_{N} \geq 0$. This specification builds on Rotemberg's (1982) quadratic cost of price adjustment. Drawing from Ireland (2001), the adjustment cost is related to changes in firm $n$ 's price inflation relative to the past observed inflation rate in the nontradable goods sector as a whole. This allows the model to reproduce realistic inflation dynamics encompassing nominal inertias and staggering. ${ }^{9}$

\footnotetext{
${ }^{9} \mathrm{~A}$ variant of the model adds another quadratic term to the adjustment cost, penalizing changes of the nominal price $p_{t}(n) / p_{t-1}(n)$ relative to a parameter $\pi$, which is equal to the gross steady-state rate of inflation $\pi>0$.
} 
The price-setting problem is then characterized as:

$$
\begin{aligned}
& \max _{\left\{p_{\tau}(n)\right\}_{\tau=t}^{\infty}} E_{t} \sum_{\tau=t}^{\infty}\left\{D_{t, \tau}\left(p_{\tau}(n)-M C_{\tau}(n)\right) p_{\tau}(n)^{-\theta}\left(P_{N, \tau}\right)^{\theta}\right. \\
& \left.*\left(N_{N, \tau}+\eta\left(Q_{\tau}+M_{\tau}\right)+G_{N, \tau}\right)\left(1-\Gamma_{P N, \tau}(n)\right)\right\}
\end{aligned}
$$

where the discount rate $D_{t, \tau}$ (with $D_{t, t}=1$ ) is the intertemporal marginal rate of substitution in consumption of the representative household, to be defined below. Note that when prices are fully flexible $\left(\phi_{N}=0\right)$, the optimization problem collapses to the standard markup rule:

$$
p_{t}(n)=\frac{\theta}{\theta-1} M C_{t}(n)
$$

where the fixed gross markup $\theta /(\theta-1)$ is a negative function of the elasticity of input substitution.

Consider now the price-setting problem in the Home tradable goods sector. Each firm $h$ has to set two (wholesale) prices, $\bar{p}(h)$ in the Home market and $\bar{p}^{*}(h)$ in the Foreign market. Denoting the nominal exchange rate as $\mathcal{E}$ (defined as Home currency per unit of Foreign currency), firm $h$ sets its prices by maximizing its profits as follows:

$$
\begin{aligned}
& \max _{\left\{\bar{p}_{\tau}(h), \bar{p}_{\tau}^{*}(h)\right\}_{\tau=t}^{\infty}} E_{t} \sum_{\tau=t}^{\infty} D_{t, \tau}\left\{\left(\bar{p}_{\tau}(h)-M C_{\tau}(h)\right)\left(\frac{\bar{p}_{\tau}(h)+\eta P_{N, \tau}}{P_{Q, \tau}}\right)^{-\theta} Q_{\tau}\left(1-\Gamma_{P Q, \tau}(h)\right)\right. \\
& \left.+\left(\mathcal{E}_{\tau} \bar{p}_{\tau}^{*}(h)-M C_{\tau}(h)\right)\left(\frac{\bar{p}_{\tau}^{*}(h)+\eta^{*} P_{N, \tau}^{*}}{P_{M, \tau}^{*}}\right)^{-\theta} M_{\tau}^{*}\left(\frac{1-s}{s}\right)\left(1-\Gamma_{P M, \tau}^{*}(h)\right)\right\}
\end{aligned}
$$

where the costs $\Gamma_{P Q, t}(h)$ and $\Gamma_{P M, t}^{*}(h)$ are the analogs of $(17)$.

If nominal rigidities in the export market are highly relevant, the prices of Home goods in the Foreign market will be characterized by significant inertia. ${ }^{10}$ In this case, exchange rate pass-through in the Foreign economy will be rather low due to the fact that prices are sticky in the consumer currency, that is, exports are invoiced in Foreign currency. However, it is worth emphasizing that in our model exchange rate pass-through may be low for reasons unrelated to nominal rigidities.

\footnotetext{
${ }^{10}$ Substantially, this is the "local currency pricing" scenario analyzed by Devereux and Engel (2000), Corsetti and Pesenti (2001a) and others.
} 
To clarify this point, note that in the absence of price stickiness prices would be equal to:

$$
\bar{p}_{t}(h)=\frac{\theta}{\theta-1} M C_{t}(h)+\frac{\eta}{\theta-1} P_{N, t}, \quad \mathcal{E}_{t} \bar{p}_{t}^{*}(h)=\frac{\theta}{\theta-1} M C_{t}(h)+\frac{\eta^{*}}{\theta-1} \mathcal{E}_{t} P_{N, t}^{*}
$$

The presence of distribution services intensive in local inputs implies that the elasticity of demand for any brand is not necessarily the same across markets. As a result, firm $h$ will in general charge different prices at Home and abroad. As stressed by Corsetti and Dedola (2002), exchange rate pass-through is less than perfect (that is, $\partial \log \bar{p}_{t}^{*}(h) / \partial \log \mathcal{E}_{t}<1$ ) and the law of one price does not hold (that is, $\bar{p}_{t}(h) \neq \mathcal{E}_{t} \bar{p}_{t}^{*}(h)$ ) even if wholesale prices are fully flexible. Asymmetries in relative productivity, relative wages, or relative costs of capital drive a wedge between Home and Foreign prices of a good $h$. Markups in both markets are state-contingent and vary as functions of productivity and demand shocks. ${ }^{11}$ Foreign variables are similarly characterized.

\subsection{Tradable inputs}

In this section, we model tradable upstream inputs used up in the production of downstream intermediate goods. These inputs can be thought of as raw and semi-finished materials or parts. It is assumed that market power in these sectors is negligible, and there is no price discrimination across countries.

Notational conventions and modeling strategy are very similar to the ones adopted above. Symmetric Home firms producing raw materials are indexed by $o \in[0, s]$. Raw materials are produced with labor, capital, and land $L$ (non-reproducible resources):

$$
T_{O, t}^{S}(o)=Z_{O, t}\left\{\left(1-\alpha_{O}-\gamma_{O}\right)^{\frac{1}{\xi_{O}}} \ell_{t}(o)^{1-\frac{1}{\xi_{O}}}+\alpha_{O}^{\frac{1}{\xi_{O}}} K_{t}(o)^{1-\frac{1}{\xi_{O}}}+\gamma_{O}^{\frac{1}{\xi_{O}}} L_{t}(o)^{1-\frac{1}{\xi_{O}}}\right\}^{\frac{\xi_{O}}{\xi_{O}-1}}
$$

where $Z_{O}$ is a productivity disturbance term.

\footnotetext{
${ }^{11}$ Similar considerations apply to the retail (consumer) market.
} 
Firm $o$ takes all prices as given, including the price of land $P_{L}$, and minimizes $W_{t} \ell_{t}(o)+$ $R_{t} K_{t}(o)+P_{L, t} L_{t}(o)$ subject to (22), obtaining expressions for $\ell_{t}^{D}(o), K_{t}^{D}(o)$, and $L_{t}^{D}(o)$. The Home price of Home raw materials, $P_{Q O}$, is equal to firm o's marginal cost:

$$
P_{Q O, t}=\frac{\left[\left(1-\alpha_{O}-\gamma_{O}\right) W_{t}^{1-\xi_{O}}+\alpha_{O} R_{t}^{1-\xi_{O}}+\gamma_{O} P_{L, t}^{1-\xi_{O}}\right]^{\frac{1}{1-\xi_{O}}}}{Z_{O, t}}
$$

and, in the absence of pricing to market, the law of one price holds:

$$
P_{M O, t}^{*}=P_{Q O, t} / \mathcal{E}_{t}
$$

Similar considerations hold in the Foreign country.

\subsection{Household optimization}

In each country there is a continuum of symmetric households. Home households are indexed by $j \in[0, s]$ and Foreign households by $j^{*} \in(s, 1]$, the same indexes of labor inputs.

Households' preferences are additively separable in consumption and labor effort. Denoting with $\mathcal{W}_{t}(j)$ the lifetime expected utility of Home agent $j$, we have:

$$
\mathcal{W}_{t}(j) \equiv E_{t} \sum_{\tau=t}^{\infty} \beta^{\tau-t}\left[U\left(C_{\tau}(j)\right)-V\left(\ell_{\tau}(j)\right)\right]
$$

where $\beta$ is the discount rate. There is habit persistence in consumption according to the specification:

$$
U_{t}(j)=Z_{U, t} \frac{\left(C_{t}(j)-b C_{t-1}\right)^{1-\sigma}-1}{1-\sigma}
$$

where $C_{t-1}$ is past per-capita Home consumption and $0<b<1$. The term $Z_{U}$ is a preference shock common to all Home residents. The parametric specification of $V$ is:

$$
V_{t}(j)=Z_{V, t} \frac{\ell_{t}(j)^{1+\zeta}}{1+\zeta}
$$

where $\zeta>0$ and $Z_{V, t}$ is a shock to labor disutility. Foreign agent $j^{*}$ 's preferences are similarly specified. The discount rate $\beta$ is assumed to be identical across countries. 
The individual flow budget constraint for agent $j$ in the Home country is:

$$
\begin{aligned}
& \mathcal{M}_{t}(j)+\mathcal{E}_{t} B_{t+1}^{*}(j)+B_{t+1}(j) \leq \mathcal{M}_{t-1}(j)+\left(1+i_{t}^{*}\right)\left[1-\Gamma_{B, t}\right] \mathcal{E}_{t} B_{t}^{*}(j) \\
& +\left(1+i_{t}\right) B_{t}(j)+R_{t} K_{t}(j)+P_{L, t} L_{t}(j)+W_{t}(j) \ell_{t}(j)\left[1-\Gamma_{W, t}(j)\right] \\
& -P_{t} C_{t}(j)\left[1+\Gamma_{S, t}(j)\right]-P_{t} I_{t}(j)+\Phi_{t}-N E T T_{t}(j)
\end{aligned}
$$

Home agents hold domestic money $\mathcal{M}$ and two bonds, $B$ and $B^{*}$, denominated in Home and Foreign currency, respectively. The short-term nominal rates $i_{t}$ and $i_{t}^{*}$ are paid at the beginning of period $t$ and are known at time $t-1 .{ }^{12}$ The two short-term rates are directly controlled by the national governments. Only the Foreign-currency bond is traded internationally: the Foreign bond is in zero net supply worldwide, while the Home bond is in zero net supply at the domestic level.

The financial friction $\Gamma_{B}$ is introduced to guarantee that net asset positions follow a stationary process and the economies converge asymptotically to a steady state. ${ }^{13}$ Home agents face a transaction cost $\Gamma_{B}$ when they take a position in the Foreign bond market. This cost depends on the average net asset position of the whole economy and is zero only when Home agents do not hold any Foreign-currency assets. Specifically, we adopt the following functional form:

$$
\Gamma_{B, t+1}=\phi_{B 1} \frac{\exp \left(\phi_{B 2} \mathcal{E}_{t} B_{H, t+1}^{*} / P_{t}\right)-1}{\exp \left(\phi_{B 2} \mathcal{E}_{t} B_{H, t+1}^{*} / P_{t}\right)+1}+Z_{B, t}
$$

with $0 \leq \phi_{B 1} \leq 1, \phi_{B 2}>0$ and $B_{H}^{*} \equiv(1 / s) \int_{0}^{s} B^{*}(j) d j$, representing per-capita Home holdings of the Foreign bond.

When $B_{H}^{*}$ is zero, $\Gamma_{B}=0$. When Home is a net lender and holdings of the Foreign bond go to infinity, $\Gamma_{B}$ rises from zero to $\phi_{B 1}$, implying that Home households lose an increasing

\footnotetext{
${ }^{12}$ We adopt the notation of Obstfeld and Rogoff (1996, ch.10). Specifically, our timing convention has $B_{t}(j)$ and $B_{t}^{*}(j)$ as agent $j$ 's nominal bonds accumulated during period $t-1$ and carried over into period $t$.

${ }^{13}$ A similar modeling strategy is adopted by Benigno (2001). Alternative approaches to guarantee stationarity rely on parametric assumptions as in Corsetti and Pesenti (2001b) or demographic dynamics as in Ghironi and Rebucci (2002).
} 
fraction of their Foreign bond returns to financial intermediaries. ${ }^{14}$ Similarly, when Home is a net borrower and holdings of the Foreign bond go to minus infinity, $\Gamma_{B}$ falls from zero to $-\phi_{B 1}$ implying that Home households pay an increasing intermediation premium on their debt. This guarantees that in a non-stochastic steady state Home agents have no incentive to hold Foreign bonds and net asset positions are zero worldwide. The parameter $\phi_{B 2}$ controls the flatness of the $\Gamma_{B}$ function, hence the speed of convergence to the steady state. The variable $Z_{B, t}$ is a noise term: uncertainty in international financial intermediation plays in GEM the same role that "uncovered interest parity shocks" or risk-premium fluctuations play in other open-economy models (such as McCallum and Nelson (1999) or Kollmann (2001)).

Home agents rent land to Home firms at the nominal rate $P_{L}$ and accumulate Home physical capital which they rent to Home firms at the nominal rate $R$. The supply of land is exogenous, say $L_{t}(j)=\bar{L}_{t}(j)$. The law of motion of capital is:

$$
K_{t+1}(j)=(1-\delta) K_{t}(j)+\Psi_{t} K_{t}(j) \quad 0<\delta \leq 1
$$

where $\delta$ is the depreciation rate. To simulate realistic investment flows, capital accumulation is subject to adjustment costs. The specific functional form we adopt is quadratic:

$$
\Psi_{t} \equiv \frac{I_{t}(j)}{K_{t}(j)}-\frac{\phi_{I 1}}{2}\left(\frac{I_{t}(j)}{K_{t}(j)}-\delta\left(1+Z_{I, t}\right)\right)^{2}-\frac{\phi_{I 2}}{2}\left(\frac{I_{t}(j)}{K_{t}(j)}-\frac{I_{t-1}}{K_{t-1}}\right)^{2}
$$

where $\phi_{I 1}, \phi_{I 2} \geq 0$ and $Z_{I, t}$ is a temporary shock (an unexpected increase in $Z_{I, t}$ is equivalent to an increase in the rate of capital depreciation that raises investment relative to baseline).

Each household is the monopolistic supplier of a labor input $j$. Using (14) and its analogs, total demand for type $j$ input is:

$$
\int_{0}^{s} \ell_{t}^{D}(n, j) d n+\int_{0}^{s} \ell_{t}^{D}(h, j) d h+\int_{0}^{s} \ell_{t}^{D}(o, j) d o=\left(\frac{W_{t}(j)}{W_{t}}\right)^{-\phi} \ell_{t}
$$

\footnotetext{
${ }^{14}$ It is assumed that all intermediation firms are owned by Home residents, and that their revenue is rebated to Home households in a lump-sum fashion.
} 
where $\ell_{t}$ is per-capita total labor in the Home economy. Each household sets the nominal wage for input type $j$ accounting for (32). Following Kim (2000), there is sluggish wage adjustment due to resource costs that are measured in terms of the total wage bill. The adjustment cost is denoted $\Gamma_{W, t}$, with:

$$
\Gamma_{W, t}(j) \equiv \frac{\phi_{W}}{2}\left(\frac{W_{t}(j) / W_{t-1}(j)}{W_{t-1} / W_{t-2}}-1\right)^{2}
$$

where $\phi_{W} \geq 0$. As was the case for prices above, wage adjustment costs are related to changes in wage inflation relative to the past observed rate for the whole economy.

Consumption spending is subject to a proportional transaction cost $\Gamma_{S}$ that depends on the household's money velocity $v$, where $v_{t}(j) \equiv P_{t} C_{t}(j) / \mathcal{M}_{t}(j)$. Agents choose their stock of real money holdings $\mathcal{M} / P$ optimally, so that at the margin shopping costs measured in terms of foregone consumption are equal to the benefits from investing in yield-bearing assets. $^{15}$

Home agents own all Home firms and there is no international trade in claims on firms' profits. The variable $\Phi$ includes all profits accruing to Home households, plus all Homecurrency revenue from nominal and real adjustment rebated in a lump-sum way to all Home households, plus revenue from financial intermediation, which is assumed to be provided by Home firms exclusively.

Finally, Home agents pay lump-sum (non-distortionary) net taxes $N E T T_{t}(j)$ denominated in Home currency. Similar relations hold in the Foreign country, with the exception of the intermediation frictions in the financial market.

The representative Home household chooses bond and money holdings, capital and consumption paths, and sets wages to maximize its expected lifetime utility (25) subject to (28)

\footnotetext{
${ }^{15}$ Following Schmitt-Grohe and Uribe (2003), the particular functional form for the transaction cost is:

$$
\Gamma_{S}\left(v_{t}\right)=\phi_{S 1} v_{t}+\frac{\phi_{S 2}}{v_{t}}-2 \sqrt{\phi_{S 1} \phi_{S 2}}
$$
}


and (30), and taking into account (32). Defining the variable $D_{t, \tau}$ as:

$$
D_{t, \tau} \equiv \beta \frac{P_{t} U^{\prime}\left(C_{\tau}\right)\left[1+\Gamma_{S, t}+\Gamma_{S, t}^{\prime} v_{t}\right]}{P_{\tau} U^{\prime}\left(C_{t}\right)\left[1+\Gamma_{S, \tau}+\Gamma_{S, \tau}^{\prime} v_{\tau}\right]},
$$

which is Home agents' stochastic discount rate and the Home pricing kernel, the first-order conditions with respect to $B_{t+1}(j)$ and $B_{t+1}^{*}(j)$ are, respectively:

$$
1=\left(1+i_{t+1}\right) E_{t} D_{t, t+1}=\left(1+i_{t+1}^{*}\right)\left(1-\Gamma_{B, t+1}\right) E_{t}\left(D_{t, t+1} \frac{\mathcal{E}_{t+1}}{\mathcal{E}_{t}}\right)
$$

The above expression is the risk-adjusted uncovered interest parity equilibrium, accounting for the fact that the return on lending to Foreign is reduced (and the cost of borrowing from Foreign is increased) by the costs of intermediation $\Gamma_{B} \cdot{ }^{16}$ In a non-stochastic steady state, the interest differential $(1+i) /\left(1+i^{*}\right)$ is equal to the steady-state nominal depreciation rate of the Home currency, and $1+i=\pi / \beta$, where $\pi$ is the gross steady-state inflation rate and $1 / \beta$ is the steady-state gross real rate of interest (equal to the rate of time preference).

The first-order conditions with respect to $\mathcal{M}_{t}(j), K_{t+1}(j)$ and $W_{t}(j)$ are standard. Real money balances $M / P$ are a positive function of consumption and a negative function of the nominal interest rate. Capital accumulation is linked to the behavior of the real price of capital $R / P$. In steady state, $1+R / P$ is equal to the sum of the rate of time preference, $1 / \beta$, and the rate of capital depreciation, $\delta$. Also, in steady state the real wage $W / P$ is equal to the marginal rate of substitution between consumption and leisure, $V^{\prime} / U^{\prime}$, augmented by the markup $\phi /(\phi-1)$ which reflects monopoly power in the labor market.

Optimization implies that households exhaust their intertemporal budget constraint: the flow budget constraint (28) hold as equality and the transversality condition is satisfied:

$$
\lim _{\tau \rightarrow \infty} E_{t} D_{t, \tau}\left[\mathcal{M}_{\tau-1}(j)+\left(1+i_{\tau}\right) B_{\tau}(j)+\left(1+i_{\tau}^{*}\right)\left(1-\Gamma_{B, \tau}\right) \mathcal{E}_{\tau} B_{\tau}^{*}(j)\right]=0
$$

Similar results characterize the optimization problem of Foreign agent $j^{*}$.

\footnotetext{
${ }^{16}$ Note that $Z_{B, t}$ is known at time $t$, the same time period when the governments set the nominal rates $i_{t+1}$ and $i_{t+1}^{*}$ and private agents choose their portfolio holdings $B_{t+1}^{*}(j)$ and $B_{t+1}^{*}\left(j^{*}\right)$.
} 


\subsection{Government}

Public spending falls on nontradable goods, both final and intermediate. In the model, $G_{A}$ is per-capita public purchases of Home final goods (a random variable in our simulation), and $G_{N}$ is per-capita public purchases of Home intermediate nontradable goods. Governments finance public expenditure through net lump-sum taxes and seigniorage revenue. The budget constraint of the Home government is:

$$
s P_{t} G_{A, t}+s P_{N, t} G_{N, t} \leq \int_{0}^{s} N E T T_{t}(j) d j+\int_{0}^{s}\left[\mathcal{M}_{t}(j)-\mathcal{M}_{t-1}(j)\right] d j
$$

The government controls the short-term rate $i_{t+1}$. Monetary policy is specified in terms of annualized interest rate rules of the form:

$$
\begin{aligned}
& \left(1+i_{t+1}\right)^{4}-1=\omega_{i}\left[\left(1+i_{t}\right)^{4}-1\right] \\
& +\left(1-\omega_{i}\right)\left[\left(1+\overline{i_{t+1}}\right)^{4}-1\right]+\omega_{1} E_{t}\left[\frac{P_{t+\tau}}{P_{t+\tau-4}}-\Pi_{t+\tau}\right]+\Theta\left(\digamma_{t}\right)
\end{aligned}
$$

where the left-hand side is the annualized interest rate, $i_{t}$ is the lagged interest rate (with $0<$ $\left.\omega_{i}<1\right)$ and $\overline{i_{t+1}}$ is the desired interest rate, defined as $\left(1+\overline{i_{t+1}}\right)^{4}=E_{t} \beta^{-4} P_{t+\tau} / P_{t+\tau-4}$. In the expression above, $P_{t+\tau} / P_{t+\tau-4}$ is the year-on-year gross CPI inflation rate $\tau$ quarters into the future, and $\Pi_{t+\tau}$ is the year-on-year gross inflation target $\tau$ quarters into the future. The term $\Theta$ is a function of a set $\digamma_{t}$ of observable variables (output gap, exchange rate, etc.) expressed as deviations from their targets, determining feedback rules for the nominal interest rate. ${ }^{17}$

Foreign variables are similarly characterized. Any steady-state discrepancy between $i$ and $i^{*}$ (thus, between $\pi$ and $\pi^{*}$ ) determines the steady-state rate of exchange rate depreciation (for $\pi>\pi^{*}$ ) or appreciation (for $\pi<\pi^{*}$ ).

\footnotetext{
${ }^{17}$ In a steady state with constant inflation target $\Pi$ we have $\pi=\left(P_{t} / P_{t-4}\right)^{0.25}=\Pi^{0.25}=\beta\left(1+i_{t+1}\right)=$ $\beta\left(1+\overline{i_{t+1}}\right)$.
} 


\section{$2.9 \quad$ Market clearing}

The model is closed by imposing the following resource constraints and market clearing conditions. The resource constraint for Home raw materials is:

$$
\int_{0}^{s} T_{O, t}^{S}(o) d o \geq \int_{0}^{s} Q_{O, t}^{D}(n) d n+\int_{0}^{s} Q_{O, t}^{D}(h) d h+\int_{s}^{1} M_{O, t}^{D *}\left(n^{*}\right) d n^{*}+\int_{s}^{1} M_{O, t}^{D *}(f) d f
$$

while the resource constraint for each nontradable $n$ is:

$$
N^{S}(n) \geq \int_{0}^{s} N_{N, t}^{D}(n, x) d x+\eta\left(Q_{t}+M_{t}\right)+G_{N, t}
$$

The Home tradable $h$ can be used by Home firms or imported by Foreign firms, so that:

$$
T^{S}(h) \geq \int_{0}^{s} Q_{t}^{D}(h, x) d x+\int_{s}^{1} M_{t}^{* D}\left(h, x^{*}\right) d x^{*}
$$

The Home final good can be used for private consumption $C$, government consumption $G_{A}$ and investment $I$ :

$$
\int_{0}^{s} A_{t}(x) d x \geq \int_{0}^{s} C_{t}(j)\left[1+\Gamma_{S, t}(j)\right] d j+s G_{A, t}+\int_{0}^{s} I_{t}(j) d j
$$

The resource constraints for labor and capital are:

$$
\begin{aligned}
& \ell_{t}(j) \geq \int_{0}^{s} \ell_{t}^{D}(n, j) d n+\int_{0}^{s} \ell_{t}^{D}(h, j) d h+\int_{0}^{s} \ell_{t}^{D}(o, j) d o \\
& \int_{0}^{s} K_{t}(j) d j \geq \int_{0}^{s} K_{t}^{D}(n) d n+\int_{0}^{s} K_{t}^{D}(h) d h+\int_{0}^{s} K_{t}^{D}(o) d o
\end{aligned}
$$

while land is in fixed (exogenous) supply:

$$
\int_{0}^{s} \bar{L}_{t}(j) d j \geq \int_{0}^{s} L_{t}^{D}(o) d o
$$

Similar expressions hold abroad. Finally, market clearing in the asset market requires:

$$
\int_{0}^{s} B_{t}(j) d j=0 \quad \int_{0}^{s} B_{t}^{*}(j) d j+\int_{s}^{1} B_{t}^{*}\left(j^{*}\right) d j^{*}=0
$$

By aggregating the budget constraints across private and public agents we derive expressions for the nominal current account and gross national product. ${ }^{18}$

\footnotetext{
${ }^{18}$ In the simulation exercises, our measure of real (constant-dollar) GDP is obtained by evaluating expenditures using fixed (steady-state) relative prices.
} 


\section{Solution, calibration and model properties}

\subsection{Solution methods}

To solve the model we first rely upon Newton-based techniques to obtain the steady-state solution of the nonlinear model. The model is then linearized and we use the standard tools that have been developed in DYNARE to study the properties of linear SDGE models. ${ }^{19}$ The particular technique used to evaluate the steady-state solution is a DAC (Divide-AndConquer) algorithm. The basic strategy behind DAC algorithms is to solve complex nonlinear problems by breaking them down into a series of less complicated problems. The DAC algorithm exploits the robustness and efficiency properties of Newton-based algorithms and has been designed explicitly to deal with large models like GEM in which important nonlinearities arise directly from the model's theoretical structure. ${ }^{20}$ The DAC algorithm is used extensively to calibrate the initial steady-state baseline solution as well as to study the nonlinear model's properties in response to permanent shocks. ${ }^{21}$

The steady-state solution strategy with the DAC algorithm involves two steps. First, we start with a parameterization of the model that guarantees an "easy" solution with a Newton-based algorithm. This will be the case when the model is approximately linear. ${ }^{22}$ Second, after obtaining an initial set of values for the endogenous variables, we then

\footnotetext{
${ }^{19}$ The DYNARE toolbox derives the reduced-form representation of the model and then provides standard moments based on assumptions about the stochastic forcing processes. In addition, it automatically provides stability and eigenvalue analysis, plots impulse response functions, and computes the contribution of variability in the stochastic forcing processes to each endogenous variable.

${ }^{20}$ For more details on the tools that have been developed to study SDGE models and how we obtain the steady-state solution of the model see Juillard and Laxton (2003).

${ }^{21}$ The permanent disinflation shocks reported below were derived using a Newton-based perfect-foresight simulation algorithm available in portable TROLL. For the properties of these algorithms see Armstrong et al. (1998) and Juillard et al. (1998).

${ }^{22}$ If the model is exactly linear, Newton's method is guaranteed to find the solution in one iteration if a
} 
gradually adjust the parameters and exogenous variables towards their desired values in sufficiently small steps that allow Newton's method to find solutions extremely rapidly. ${ }^{23}$

\subsection{Estimates of macroeconomic variability and calibration of the stochastic processes}

While the model introduced in the previous section shares many characteristics with other recent SDGE models, it also exhibits a number of relatively novel features (such as the two-stage trade structure, the inclusion of nontradable goods, the presence of a distribution sector) not unique to the model but still non-standard in the literature, ${ }^{24}$ and encompasses a large number of sources of uncertainty. These features provide greater flexibility to fit the data and simulate realistic interdependencies between a small "representative" transition country (the "Home" country of our quarterly model) and the block of Euro countries (the "Foreign" country), as we discuss in what follows.

Table 1 provides some estimates of macroeconomic variability based on standard deviations of detrended data for both the Euro area and the Czech Republic. ${ }^{25}$ As shown in the table, real GDP has been about twice as volatile in the Czech Republic as it has been in the Euro area. Table 1 also includes estimates of variability for consumption, investment, government absorption, exports and imports. For the Euro area these measures suggest

solution exists. If the model is approximately linear, Newton's method will find the true solution in a few iterations provided the user has provided reasonable initial guesses for the endogenous variables.

${ }^{23}$ While Newton's method is not foolproof and does require some understanding of both the algorithm and the model that is being studied, we have found that in practise it works extremely well for building large nonlinear SDGE models like GEM.

${ }^{24}$ It is worth noticing that most models of this genre have a single productive sector.

${ }^{25}$ With the exception of the measures of inflation, interest rates and the ratios of net exports to GDP, all of the measures in Table 1 have been detrended with the HP filter using a smoothness parameter of 1600. The measures for the Euro are based on data from 1970Q1 to 2001Q4 and the measures for the Czech Republic are based on data from 1973Q1 to 2002Q4. 
that imports are the most volatile component of real GDP expenditures (with a standard deviation of 3.1 percent), followed by investment (2.7) and exports (2.4). The data also indicate that, over the long sample period covered in our analysis, detrended consumption expenditures and government absorption have displayed less variability than real GDP. ${ }^{26}$

The measures for the Czech Republic tell a different story as regards the degree of variability in the transition countries. Indeed, since 1993 all expenditure components - including consumption and government absorption - have been significantly more volatile than aggregate real GDP. Also, fluctuations of investment relative to GDP have been significantly wider in transition countries: investment has been 3.5 times more volatile than real GDP in the Czech Republic compared to 2.7 times in the Euro area. Data for Hungary and Poland present a similar pattern and suggest similar considerations about the nature of shocks to these economies. All three transition countries have experienced increases of real investment around 10-15 percentage points of GDP since 1993, and the current investment/GDP ratios are well above the aggregate ratio in the Euro area.

Measures of variability in interest rates and exchange rates are also included in Table 1. Variability in nominal interest rates has been quite high in these countries, mainly reflecting the process of disinflation. The real effective exchange rate has approximately the same degree of variability as the nominal effective exchange rate, a feature shared by many other emerging and advanced economies. A fairly strong link between productivity and the real exchange rate provides evidence in support of the Balassa-Samuleson hypothesis, ${ }^{27}$

\footnotetext{
${ }^{26}$ This feature of lower variability in consumption expenditures in advanced economies such as the Euro area is not robust to the sample period chosen. For example, over the 1990s several industrial countries have recorded greater variability in consumption expenditures than in their real GDP measures.

${ }^{27}$ For instance, Halpern and Wyplosz (2001) provide econometric evidence of a Balassa-Samuelson effect in Eastern and European countries, according to which strong productivity growth in the tradables sector results in higher real wages in both the tradables and nontradables sectors, a trend increase in the price of nontradables relative to tradables, and a strong upward trend in CPI-based real exchange rates. The original contributions are Balassa (1964) and Samuelson (1964).
} 
although other driving factors, such as a shift in tastes in more advanced economies towards the types of goods produced by transition countries, may have played a key role in affecting real exchange rate movements. ${ }^{28}$

A key stylized fact for the transition countries has been the enormous increase in the degree of openness over the time period covered by Table 1, with both the export and import ratios rising between 20 and 30 percentage points. The strong correlation between exports and imports in the transition countries reflects several factors: higher investment in the tradable goods sectors, as well as the effects of structural reforms and a production shift toward higher-quality goods in demand from more advanced economies; the intensive use of imported intermediate inputs in the production of tradable goods, as well as constraints (capital controls) that may have limited the magnitude of current account imbalances in these countries. The two-stage trade structure of our model helps rationalize these elements.

In the light of the above considerations, the model encompasses several types of stochastic shocks in both countries, as well as a "risk premium" shock $Z_{B}$. The assumptions about the shocks are reported in Table 2. These include shocks to productivity in all the sectors $\left(Z_{T}\right.$, $Z_{N}, Z_{O}$ ) as well as shocks to aggregate investment (the depreciation rate $Z_{I}$ ), consumption (the marginal utility of consumption $Z_{U}$ ), labor effort (the marginal disutility of labor effort $\left.Z_{V}\right)$, government spending $\left(G_{A}\right)$ and a preference shifter that affects the weight of tradable goods in final good production $(\gamma)$. The productivity shocks are perfectly correlated in all sectors in each country. The distributions of the shocks have been calibrated to match some of the moments reported in Table 1. For example, based on these assumptions the model generates about twice as much variability in GDP in the Czech Republic than in the Euro Area, and the absolute degrees of variability in GDP are consistent with our measures of variability in the historical data. However, there are several important differences between

\footnotetext{
${ }^{28}$ Lipschitz, Lane and Mourmouras (2002) suggest that the real exchange rate may have been very low at the start of the transition because of insufficient market penetration and product reputation in Western markets.
} 
the model's estimates of variability and the historical measures provided in Table 1.

Relative to the historical data, the model generates considerably less variability in inflation (and interest rates). This is to be expected because a maintained assumption of the analysis is that monetary policy is being governed by either an explicit (or implicit) inflation-targeting regime, where interest rates are adjusted to provide an anchor for inflation expectations. The base-case assumption for the calibration of the model assumes a Generalized Taylor rule ${ }^{29}$ with an interest rate smoothing parameter of 0.5 and a weight on inflation equal to one. As noted above, inflation and interest rate variability is considerably lower than in the historical data because the latter were affected by the disinflationary strategies pursued by the monetary authorities.

Also, the model's measure of the real exchange rate is considerably more volatile than the historical data for the Czech republic. In fact, monetary policy regimes in place before the adoption of inflation targeting in May 1997 were designed to explicitly reduce variability in the exchange rate. The sample period is rather limited, but variability in the detrended real exchange rate has been significantly higher since 1997. In $G E M$, shocks to the risk premium induce significant variability in the components of aggregate demand and this may explain, for example, why consumption variability can be significantly higher than variability in real GDP in emerging economies.

\subsection{Baseline parameters}

We now discuss the key aspects of our base-case calibration. The Home country size $s$ relative to World is measured in terms of (relative) GDP. We set $s$ at 5 percent. The discount rate $\beta$ (the reciprocal of the steady-state real interest rate) is similar in the two countries. A typical yearly calibration for the real interest rate is $3-4$ percent. We follow Christiano, Eichenbaum and Evans (1999) and set $\beta=1.03^{-0.25}$.

\footnotetext{
${ }^{29}$ See Section 4 below.
} 
The elasticities of substitution among differentiated intermediate goods, $\theta$ and $\theta^{*}$, are evaluated to match existing estimates of steady-state price markups such as $\theta /(\theta-1)$. Martins, Scarpetta and Pilat (1996) estimate the average markup for manufacturing sectors at around 1.2 in most OECD countries over the period 1980-92. Some authors rely on lower estimates (for instance Chari, Kehoe and McGrattan (2002) choose 1.1), while other authors $^{30}$ suggest that a range between 1.2 and 1.7 may be plausible. We set $\theta /(\theta-1)=1.2$ or $\theta=6$ in both countries.

The elasticities of substitution among differentiated labor inputs, $\phi$ and $\phi^{*}$, are related to the wage markup. According to Gali, Gertler and Lopez-Salido (2002), values between 1.15 and 1.4 for the sum of the steady-state wage and price markups can be thought of as "falling within a plausible range". However, higher values may be appropriate for the euro area. For instance, Benigno and Thoenissen (2002) estimate $\phi$ at 5.1 for the UK, and 4.0 for the Euro area. Our parameterization takes $\phi=\phi^{*}=4$ in both countries.

The choice of $\gamma, \nu, \nu_{N}, \nu_{T}$ and their Foreign equivalents highlight the differences in the degrees of openness among the two economies on which our exercise is focused. We set $\gamma=.25, \gamma^{*}=.50, \nu^{*}=\nu_{N}^{*}=\nu_{T}^{*}=.98, \nu=\nu_{N}=.05, \nu_{T}=.02$. Our calibration implies that in the Home country the import share of downstream intermediate goods is equal to 19.9 percent and the import share of upstream raw materials is equal to 17.4 percent, roughly equally distributed among tradable and nontradable goods. ${ }^{31}$

For the Foreign country, we assume that the weight of capital in production is the same in both sectors that produce intermediate goods for final consumption and set $a_{N}^{*}=\alpha_{T}^{*}=0.33$. We assume a relatively higher value for the weight of capital in the Home country based on estimates provided by the Czech National Bank $\left(a_{N}=\alpha_{T}=0.40\right)$. The weights of raw materials are $\gamma_{N}^{*}=\gamma_{T}^{*}=0.3, \gamma_{N}=0.1$, and $\gamma_{T}=0.5$. The production of raw materials and

\footnotetext{
${ }^{30}$ See e.g. Morrison (1994) or Domowitz, Hubbard and Petersen (1988).

${ }^{31}$ These import shares figures are based on recent estimates by the Czech National Bank of the trade volumes between the Czech Republic and the Euro area.
} 
semi-finished goods is assumed to use a non-reproducible resource (referred to as "land") in exogenous supply. In both countries the combined income share of capital and land is assumed to be 0.3 , with two-thirds of this income stream accruing to capital and one third to land $\left(\alpha_{O}=\alpha_{O}^{*}=0.20\right.$ and $\left.\gamma_{O}=\gamma_{O}^{*}=0.10\right)$. These parameters values interact with the import shares and generate steady-state labor shares in total GDP of about 65 percent both in the Euro area and in the transition country.

The elasticity of substitution between tradable goods and nontradable goods in final good production $\varepsilon$ is set at 1.1 in both countries. The elasticity of substitution between intermediate exportables and importables in the Home country is also set at 1.1, but is significantly higher in the Foreign country, where $\varepsilon_{Q M}^{*}=4$. These choices are broadly in line with other studies, although the range of plausible options is rather large. Empirical studies of the price elasticity of import demand such as Hooper and Marquez (1995) report a median value of 0.6 for Japan, Germany and UK. Gali and Monacelli (2002) choose $\varepsilon=1$ as their baseline. Other studies (including Chari, Kehoe and McGrattan (2002), and Smets and Wouters (2002a)) set the elasticity of substitution between Home and Foreign goods at 1.5 .

The elasticities of input substitution in the production of intermediate tradable goods and nontradable goods and raw materials $\left(\xi_{N}, \xi_{T}, \xi_{O}\right)$ are all set at .75 in both countries, significantly below the customary unit elasticity associated with Cobb-Douglas production functions. This choice allows us to simulate a lesser response of capital to interest rate changes than would be the case under a Cobb-Douglas calibration. As opposed to labor and capital, domestic and imported raw materials are highly substitutable in production. Correspondingly, we set the elasticities $\left(\xi_{O N}, \xi_{O T}\right)$ at 3 in both countries.

Burstein, Neves and Rebelo (2003) highlight the link between $\eta$ and the wholesale/retail margin and set the parameters $\eta$ and $\eta^{*}$ equal to 1 . However, in our model the wholesale/retail margin is a function of other structural parameters such as the demand elas- 
ticities, and the choice of the distribution parameter $\eta$ also affects the degree of exchange rate pass-through. Our baseline is $\eta=.2$ in the Home country and $\eta^{*}=.35$ in the euro area, implying ceteris paribus a higher degree of pass-through in the emerging economy, consistent with empirical evidence. ${ }^{32}$

The parameterization of the marginal utility of consumption relies on a combination of high habit persistence $(b=.95)$ and high intertemporal substitution $(\sigma=1 / 3)$. This specification is unorthodox but certainly not unprecedented: for instance, Rotemberg and Woodford (1998) adopt $\sigma=0.16$ coupled with the assumption that households choose their index of purchases $C_{t}$ at time $t-2$, thus making expenditures decisions predetermined with respect to the timing of interest rate shocks. Experiments with alternative parameters are conducted in sensitivity analysis.

The marginal disutility of labor effort is $V^{\prime}=\ell^{\zeta}$. Micro-data estimates of $\zeta$ consider $[3,20]$ as a reasonable range. For instance, Gali, Gertler and Lopez-Salido (2002) take $\zeta=5$ as their baseline. But other authors, e.g. Kollmann (2001), choose $\zeta=0$ (linear disutility of labor) following the real business cycle literature. Our benchmark parameterization is $\zeta=2.5$ in both countries.

Aggregate data suggest an annual depreciation rate for capital of about 10 percent, so $\delta=\delta^{*}=0.025$. The adjustment cost parameters for capital accumulation, $\phi_{I 1}$ and $\phi_{I 2}$, are chosen as to match the fact that the standard deviation of investment is typically observed to be 3-4 times larger than the standard deviation of GDP.

The transaction-cost parameters in the bond market are $\phi_{B 1}=0.05$ and $\phi_{B 2}=0.1$, leading to a very slow reversion of the net asset position between Home and Foreign to its steady-state value. This feature guarantees that in the short and medium term the properties of the model - especially the degree of persistence of bond holdings and the dynamics of the current account — are virtually unaffected by the asymptotic convergence

\footnotetext{
${ }^{32}$ See Campa and Goldberg (2001).
} 
condition. Money demand plays a residual role in our model. We follow Schmitt-Grohe and Uribe (2001) and set $\phi_{S 1}=0.011$ and $\phi_{S 2}=0.075$ in both countries, consistent with their estimates of money demand in the US.

As ratios of steady-state GDP, government spending $G_{N}$ is set at 10 percent and $G_{A}$ is set at 5 percent in the two countries, broadly in line with the observed shares of government consumption (assumed to fall exclusively on intermediate nontradable goods) and investment (assumed to have the same composition of private investment).

The base-case calibration of the model assumes a significant degree of structural inflation persistence in wages and prices of the intermediate goods in both the tradable goods and nontradable goods sectors (controlled by $\phi_{N}, \phi_{T}, \phi_{W}$ and their Foreign analogs). The adjustment cost parameters that determine the degree of structural inflation persistence were calibrated to be consistent with a sacrifice ratio of 2.1 in the Foreign country and 1.1 in the Home country. ${ }^{33}$ This assumption implies values for $\phi_{N}, \phi_{T}, \phi_{W}$ around 400 in the Home country and twice this magnitude for the Foreign country. In addition, the base-case calibration of the model assumes that export prices respond instantaneously to changes in exchange rates $\left(\phi_{M}=\phi_{M}^{*}=0\right)$ : as discussed above, because of the presence of a distribution sector there will be incomplete pass-through of the exchange rate to the prices of intermediate goods even when export prices are fully flexible. Yet, in sensitivity analysis we consider the effects of lowering short-run pass-though by increasing the adjustment costs for export prices $\phi_{M}$ and $\phi_{M}^{*}$.

\footnotetext{
${ }^{33}$ The sacrifice ratio is defined as the cumulative annual output gap that is required to permanently reduce inflation by one percentage point. Estimates of sacrifice ratios are typically smaller in emerging market economies than in relatively closed economies like the Euro area. The estimate of a 1.1 sacrifice ratio for the Home country was based on the results of a simulation conducted at the Czech National Bank, suggesting that this is a plausible estimate of the transitory output costs of disinflation. A sacrifice ratio around 2.0 for the Foreign country is well within the range of estimates produced by other models of the Euro area.
} 


\subsection{Simulating the monetary transmission mechanism}

As mentioned earlier, our model has been calibrated to mimic closely the empirical features of the monetary transmission mechanism as estimated and relied upon for forecasting and policy analysis by central banks. In most empirical models of the monetary transmission mechanism, it is not possible for the monetary authority to change the target rate of inflation without having significant short-run effects on real variables in the economy. In addition, in the same empirically-based estimates of the monetary transmission mechanism, hikes in interest rates do not usually result in instantaneous jumps in real activity, but require several quarters to work their effects through the economy. Similar features, both qualitatively and quantitatively, appear in our simulations.

To illustrate differences and similarities between the two economies of our model, in this section we study the dynamic adjustment patterns in response to two types of policy shocks: a permanent one-percentage point disinflation shock, and a 100 basis point hike in the short-term policy rate.

\subsubsection{Permanent reduction in the target rate of inflation}

Figure 2 reports the results of an experiment where the inflation target in the Foreign country is reduced permanently by 1 percentage point. In each panel, the solid line refers to the Home country and the dashed line refers to the Foreign country. As can be seen in the two top panels of Figure 2, the presence of stickiness in the inflation process requires an increase in the nominal interest rate and leads to an appreciation of the real exchange rate. This results in a hump-shaped profile for real GDP that troughs after about four quarters, when monetary conditions ease to prevent an undershooting of the new inflation target. Since the Foreign country's external trade is relatively small (our two-country setup ignores any trade linkages between the Euro area and the rest of the world outside the emerging country), the response of real GDP is mainly determined by the response of aggregate consumption 
and investment expenditures. The response of investment to this type of aggregate demand shock is approximately three times the response of aggregate GDP, whereas consumption responds slightly less than GDP over the cycle.

The cumulative quarterly effect on the output gap in the Foreign country is 8.5, implying a sacrifice ratio of around 2.1, consistent with a fairly large body of empirical evidence according to which disinflation results in significant output costs in the short run. ${ }^{34}$ The appreciation of the real exchange rate in the Foreign country results in a loss in competitiveness and a deterioration in real exports of the Foreign country. Note, that because the Home country has significant trade linkages with the Foreign country, the overall spillover effects are contractionary on both investment and consumption in the Home country.

When conducting the same type of experiment in the Home country, real GDP in the Home country declines by a similar amount as real GDP in the Foreign country when the shock originates in the Foreign country, but in this case the cycle is significantly less protracted. Indeed, in this experiment the quarterly output gap of the Home country cumulates to 4.5 percent, implying a sacrifice ratio of 1.1. As the Home country is small, the Home shock has no discernible effect on the levels of consumption and investment in the Foreign country. ${ }^{35}$

Figure 3 compares our results for a disinflation shock in the Home country with the same experiment conducted on the Czech National Bank's Quarterly Projection Model $(C N B-Q P M)$. In the panels of Figure 3, the solid line refers to the Home country as considered in GEM, while the dashed line refers now to the Home country as considered in $C N B-Q P M{ }^{36}$ To make the results more easily comparable across models, the interest

\footnotetext{
${ }^{34}$ Micro-founded models like $G E M$ also feature interesting asymmetries where the temporary output gains associated with inflating are actually less than the temporary output losses associated with disinflation.

${ }^{35}$ These results as well as other sensitivity analysis are available upon request from the authors.

${ }^{36}$ We thank Jan Vlcek and his colleagues at the CNB for supplying us with these simulation results from CNB-QPM.
} 
rate response in $G E M$ has been tuned to equal the response from $C N B-Q P M$ for the first three-quarters of the simulation horizon. The bottom lower panels compare the responses of real GDP and CPI inflation. As Figure 3 shows, the GEM's theory-based dynamics fits quite well the reduced-form impulse responses at the CNB, and provides a satisfactory representation of the monetary transmission mechanism as embedded in the tools for policy evaluation currently in use in the Czech Republic. ${ }^{37}$ Notice that the responses of real GDP and inflation occur slightly earlier in GEM because expenditure choices are not subject to any decision lags. The introduction of predetermined expenditure ${ }^{38}$ would be necessary in $G E M$ to explain the type of dynamics that are quite common in empirically-motivated reduced-form models.

\subsection{Dynamic effects of a temporary interest rate hike}

Table 3 reports the responses of key macro variables in our model to a 1-year hike in the policy rate in the Foreign country, followed by reversal to the base-case Taylor rule. Fagan, Henry and Mestre (2001) consider the same experiment by using the ECB's AreaWide Model $(A W M)$, whose empirical apparatus does not build upon a choice-theoretic structural model. For comparison purposes, Table 3 also reports their estimates. As shown in the Table, the responses for many aggregates display a very similar profile and there are only three noteworthy exceptions.

First, the response of investment is significantly longer-lived in $A W M$, reflecting significant accelerator effects that are not uncommon in empirical reduced-form models of the monetary transmission mechanism. Such effects may be difficult to mimic in choice-theoretic models of the business cycle and indeed may reflect a misattribution of the role of supply

\footnotetext{
${ }^{37}$ In future versions of GEM, the strategy of estimation will consider information provided by models like CNB-QPM as priors, and then use Bayesian techniques to adjust these priors according to available data. See Smets and Wouters (2002b) for an application of this approach to an SDGE model of the Euro area.

${ }^{38}$ See Woodford (2002) for a textbook treatment.
} 
shocks in reduced-form models that cause more persistent movements in investment, but this remains an issue that needs to be addressed in future research.

The second difference is the response of the exchange rate. In GEM the exchange rate jumps more in the very short run than it does in $A W M$, reflecting rational behavior by forward-looking market participants as opposed to the ad-hoc treatment of expectations in empirical models. The third difference is the response of imports, which is considerably weaker in $G E M$ than in $A W M$. This is not a surprise: the two-country GEM can only account for bilateral trade between the small and large economies, while the simulation of plausible imports dynamics in the Euro would require an analytical framework in which trade linkages with third markets play a key role. ${ }^{39}$

\section{Monetary policy rules}

\subsection{Taylor rules and Inflation-Forecast-Based rules}

Over the last decade, the literature on the performance of interest rate rules in macroeconomic models has principally focused on two types of rules, both extensively used in research and policy analysis in central banks. The first one is universally referred to as the Taylor rule, following the seminal contribution by Taylor (1993) in which a simple interest rate reaction function - which depended on contemporaneous values for inflation and the output gap — provided a useful paradigm for thinking about monetary policy issues. ${ }^{40}$ The second type of monetary policy rule has come to be known as an Inflation-Forecast-Based (IFB)

\footnotetext{
${ }^{39}$ A potentially problematic aspect that may deserve further study is the assumption in GEM that interestrate sensitive demand components such as investment expenditures have the same import propensity of less-interest rate sensitive components. This extension may be incorporated into future versions of the model.

${ }^{40}$ In simulation experiments with policy rules it is usually assumed that the policymaker knows the contemporaneous values for inflation and the output gap, although in the real world even these variables need to be estimated on the basis of available information.
} 
rule, although IFB rules are simply more "forward-looking" versions of the Taylor rule, as the short-term policy rate is assumed to respond to a forecast of future inflation rather than the contemporaneous level of inflation. ${ }^{41}$

Recalling expression (38) above, the specific forms of the Taylor and IFB rules considered in this paper can be nested into our general rule once we take into account the output gap. We therefore define $\Theta\left(\digamma_{t}\right)=\omega_{2}$ ygap $_{t}$ in equation (38), where $\omega_{2} \geq 0$ and the output gap ygap is defined as the deviation of real GDP from the steady-state level implied by the model. Note that, when $\omega_{1}, \omega_{2}=0.5$, and $\omega_{i}$ and $\tau$ are set to zero, expression (38) becomes the original Taylor (1993) rule. Because the original contribution did not allow for inertia in the interest rate, we will refer to Taylor rules with inertia $\left(\omega_{i}>0\right)$ as Generalized Taylor rules, or simply GT rules. By contrast, when $\tau>0$ we will refer to the rule as an IFB rule, as the interest rate in this case depends on a forecast of the year-on-year inflation rate $\tau$ quarters into the future.

Taylor-style rules shed light on the fundamental role of monetary policy under a flexible exchange rate regime, which is to adjust the policy rate in response to movements in inflation as to provide an anchor for inflation and inflation expectations. Specifically, in a class of linear rational expectations models the asymptotic response of the policy rate with respect to inflation has to be greater than one for these models to be saddle-point stable, and response coefficients below one are associated with poor macroeconomic performance. This stability property is sometimes referred to as the Taylor principle. ${ }^{42}$ In this paper we will be relying upon linearized versions of GEM that satisfy the Taylor principle. Given our

\footnotetext{
${ }^{41}$ Based on some initial work at the Bank of Canada in the early 1990s, IFB rules have been used extensively in central banks that have implemented inflation-targeting frameworks — see Laxton, Rose and Tetlow (1993) and Black, Macklem and Rose (1997). For a critique of IFB rules and Taylor rules as well as an alternative framework see Svensson (2003) and Svensson and Woodford (2003).

${ }^{42}$ See McCallum (2002) and Woodford (1999).
} 
specification, a necessary and sufficient condition is that $\omega_{1}>0 .{ }^{43}$

A fairly comprehensive study by Levin, Wieland and Williams (2001) (hereinafter LWW) examined the robustness of IFB rules in five macroeconomic models of the US economy. The basic conclusion of their analysis was that IFB rules should respond to a one-year-ahead forecast of inflation and the current output gap, and incorporate a substantial degree of policy inertia. Indeed, the degree of inertia in the models that they studied was estimated to be approximately 1, so LWW went on to formulate a very simple IFB rule of the following form:

$$
\left(1+i_{t+1}\right)^{4}-1=\left[\left(1+i_{t}\right)^{4}-1\right]+0.4\left[\frac{P_{t+4}}{P_{t}}-\Pi_{t+4}\right]+0.4\left(\text { ygap }_{t}\right)
$$

We will refer to this simple rule as the LWW rule. A potentially important advantage of the LWW rule is that it does not depend on any direct measure of the equilibrium real interest rate, which could be a significant advantage for emerging economies that typically experience large real interest rate fluctuations. ${ }^{44}$

\subsection{Comparing optimally calibrated GT and IFB rules for the Home country}

Table 4 reports the results for GT rules in the Home country, optimally calibrated to minimize a standard loss function $\Lambda$ that depends on the unconditional variances of inflation,

\footnotetext{
${ }^{43}$ The stability conditions in nonlinear models are more complicated. For example, using a nonlinear model, Isard and Laxton (1999) show that the economy may enter the region of instability if the weight on the output gap is too high relative to the weight on inflation, even if the weight on inflation is greater than one. The emphasis on the Taylor rule and the Taylor principle has been instrumental in improving the methodology that is used to build models for monetary policy analysis. For example, it was not uncommon even as late as the 1980s to find models in policy institutions that could be simulated with exogenous interest rates. Such models by definition did not satisfy the Taylor principle.

${ }^{44}$ To the extent that measures of the equilibrium real interest rate are useful for forecasting future inflation, or even measuring the output gap, it is not clear whether problems associated with uncertainty in the equilibrium real interest rate can be overcome entirely by the simple LWW rule.
} 
output gap, and the first difference of interest rates. ${ }^{45}$ In the loss function the weight on inflation variability is 1 and the weight on interest rate variability $\left(\Lambda_{i}\right)$ is 0.5 . The four rows in Table 4 report estimates that are based on varying the weight on the output gap $\left(\Lambda_{\text {ygap }}\right)$ in the objective function from 0.5 to 2.0 in increments of 0.5 . As can be seen in the Table, optimally calibrated GT rules result in significant inertia in the policy rate (estimates of $\omega_{i}$ range from 0.91 to 0.93 ) and plausible coefficients on inflation and the output gap. Relative to the Taylor (1993) rule and the LWW rule, the main difference is that these rules place a significantly higher weight on inflation vis-à-vis the output gap.

Table 5 repeats the same exercise for an IFB rule that assumes that the policy rate depends on the one-year-ahead forecast of future inflation — that is, $\tau=4$ in equation (38) above. These results are interesting for a number of reasons. First, as in the LWW rule, the parameter on the lagged interest rate term approaches its upper bound of 1.0. Second, and unlike the LWW rule, which has equal weights on both inflation and output, this rule suggests a considerably higher weight on the inflation forecast (the values of $\omega_{1}$ range from 1.78 to 1.92 ) than the output gap (the values of $\omega_{2}$ range from 0.23 to 0.55 ). Third, the outcomes for inflation and output variability do not vary significantly over different specifications of preferences, and in all cases the model generates almost the same variability for inflation as it does for output. The only significant difference is that a higher weight on output variability in the objective function $\left(\Lambda_{\text {ygap }}\right)$ results in a slightly higher level of interest rate variability — which rises from 0.76 to 0.84 when $\Lambda_{y g a p}$ rises from 0.5 to 2.0 .

Comparing the values of the loss functions in Table 4 and Table 5 , it can be seen that the IFB rule strictly dominates the GT rule ${ }^{46}$ and the difference becomes wider the larger the weight that is placed on output variability in the objective function. However, as can be seen in the Tables, the IFB rule does not offer a substantial improvement over the GT

\footnotetext{
${ }^{45}$ The loss function is $\Lambda=\sigma_{\left(P_{t} / P_{t-4}\right)}^{2}+\Lambda_{y g a p} \sigma_{(y g a p)}^{2}+\Lambda_{i} \sigma_{\left(i_{t+1}-i_{t}\right)}^{2}$.

${ }^{46}$ This result is consistent with the findings of Batini, Harrison and Millard (2001).
} 
rule when one examines the underlying improvement in macro variability. This result is consistent with other studies that find that IFB rules offer a fairly small improvement over GT rules in linearized models of the economy. ${ }^{47}$

\subsection{Taylor efficiency frontiers}

Figure 4 summarizes the main results of our paper. The curves plot the trade-off between output and inflation variability in both the Home and Foreign countries, based on the GT rule that allows for interest rate smoothing. To make the trade-offs plausible and comparable to other studies, they have been constructed based on an assumption that the degree of interest rate variability (measured by the standard deviation of $i_{t+1}-i_{t}$ ) is less than some critical level $\bar{\sigma}_{\Delta i}$. We set the value for $\bar{\sigma}_{\Delta i}$ equal to 0.8 because this is roughly consistent with the measures reported in Tables 4 and 5 under different assumptions about preferences. ${ }^{48}$ The curves were generated by choosing the most efficient pairs of standard deviations for inflation and output by searching over thousands of combinations of $\omega_{i}, \omega_{1}$ and $\omega_{2}$ that were varied in increments of 0.01 .

The implications of openness can be seen clearly in Figure 4. Moving upward and eastward from the origin, Figure 4 first plots the Taylor frontier for the Foreign country, under our base-case set of assumptions for the distributions of the disturbance terms reported in Table 2. Next, we find the Taylor frontier for the Foreign country under the assumption that the distributions of the shocks is the same as in the Home country. ${ }^{49}$ Finally we plot

\footnotetext{
${ }^{47}$ See for example Levin, Wieland and Williams (2001) and Taylor (2000). However, IFB rules have been found to perform significantly better than Taylor rules in the presence of significant nonlinearities - see Isard, Laxton and Eliasson (1999).

${ }^{48}$ This measure for interest rate variability is also roughly consistent with the degree of variability in short-term interest rates in countries that have been successful in implementing either explicit or implicit inflation targeting strategies.

${ }^{49}$ We discuss these results in Section 4.4.
} 
the Taylor frontier for the Home country. Because the Foreign country is assumed to be relatively closed and exposed to smaller disturbances than the Home country, it is possible for the GT rule to deliver much lower variability in both output and inflation in the Foreign country than in the Home country.

\subsubsection{Results for the relatively-closed Foreign country}

The results reported in Figure 4 are consistent with previous studies of the robustness of the LWW rule in different models of the US economy. First, the generalized Taylor rule delivers low variability in both inflation and output. Second, and more importantly, the simple LWW rule lies very close to the efficiency frontier of our economy. This provides another confirmation that a simple IFB rule which places a weight of 0.4 on both inflation and output is robust across simulation models of a relatively closed economy, not necessarily confined to the US case.

Figure 4 also shows the values for output and inflation variability in the Foreign country based on the original Taylor (1993) rule. As can be seen in the Figure, the Taylor rule lies further away from the efficiency frontier than the LWW rule. Because the original Taylor (1993) rule did not include interest rate smoothing, the distance between the point associated with the original Taylor (1993) rule and the frontier can be interpreted as the benefits that can be derived by generating optimal inertia in the policy rate, as discussed by Woodford (1999).

\subsubsection{Results for the relatively-open Home country}

We can now assess how rules designed for large and relatively closed economies perform in a small and relatively open economy. The first striking result is that both the original Taylor (1993) rule and the LWW rule appear to be consistent with policy preferences that place a very high weight on stabilizing output relative to inflation. Second, in this case the LWW rule strictly dominates the Taylor (1993) rule. In fact, the LWW rule lies within the 
efficiency frontier that is generated on the basis of a generalized Taylor rule that allows for inertia in the policy rate.

Figure 4 also includes another IFB rule with $\omega_{i}=1$, where the weights on output and inflation have been optimized to minimize a standard loss function $\Lambda$ that places equal weights of 1 on both output and inflation variability and a weight of $1 / 2$ on interest rate variability (see row (2) of Table 5). We refer to this specification as the "optimized" LWW rule. Relative to the original LWW rule, this calibration process produces a smaller weight on the output gap (0.18) and a much larger weight on the deviation of one-year-ahead inflation from target (1.87). According to the optimized LWW rule, the one-year-ahead inflation forecast already embodies sufficient information about the output gap, making the output gap less important as a separate argument in the reaction function. Figure 4 shows that the optimized LWW rule yields a significantly better macroeconomic performance than GT rules. ${ }^{50}$

One obvious question remains to be answered before moving to the sensitivity analysis. If rules designed for relatively closed economies do not result in good macroeconomic performance in small, open economies, how do rules designed for small open economies perform in relatively closed economies? Point A in Figure 4 provides a preliminary answer to this question. It takes the LWW rule that has been optimized for the Home country and asks how it might perform in a relatively closed economy such as the Foreign country of our model. As can be seen in the Figure, the rule is efficient in the sense that it lies along the efficiency frontier, but the aggressive response of this rule to inflation would only be consistent with preferences that place a high weight on inflation variability relative to variability in output.

\footnotetext{
${ }^{50}$ Similar results characterize other studies of policy rules in emerging markets. For instance, in their model of the Argentinian economy Ghironi and Rebucci (2002) show that, within the class of GT rules, rules that place a large coefficient on inflation perform better.
} 


\subsection{Some sensitivity analysis}

\subsubsection{What accounts for a less favorable trade-off in the small open economy?}

To understand what accounts for the less favorable trade-off in the relatively open economy we regenerated the efficiency frontier for the relatively closed Foreign economy after imposing the same assumptions on the stochastic disturbances that we used in the calibration of the Home country. As can be seen in Figure 4, this shifts the efficiency frontier for the relatively closed economy about two thirds of the distance toward the efficiency frontier derived for the Czech Republic. The remaining gap reflects openness, or more precisely the larger effects that "risk premium" financial shocks have on the Czech Republic as well as the effects of disturbances that originate in the Euro area and are transmitted to the Czech Republic through trade and macroeconomic linkages.

\subsubsection{Different assumptions about the sensitivity of consumption to interest rate changes}

While our base-case assumptions for the intertemporal elasticity of substitution $\sigma$ and habit persistence $b$ help to match closely the properties of reduced-form, empirically-based models of the monetary transmission mechanism, they are non-standard in the relevant literature, which usually assumes an intertemporal elasticity of substitution close to one and significantly lower habit persistence. The calculations reported in Table 4 were recomputed after raising $\sigma$ from $1 / 3$ to 0.99 and reducing the habit persistence parameter $b$ from 0.95 to 0.85. Our results were not significantly affected by these changes. On balance, the new parameterization reduces the lags in the monetary transmission mechanism and makes it easier for monetary policy to deliver lower variability in output. 


\subsubsection{Is there a role for the exchange rate in monetary policy rules?}

Several experiments were performed adding measures of exchange rate depreciation to the set $\digamma_{t}$ in (38), to evaluate if policy responses to exchange rate movements are able to improve macroeconomic performance as measured by the loss functions in Tables 4 and 5. Thus far, the results suggest that there is a very small role for the exchange rate to play in the linearized version of GEM even when there are significant adjustment costs to export prices and short-run pass-through is relatively low. It may even be counterproductive for monetary policy to react strongly to movements in the exchange rate, the information content of which is already captured by either current or expected CPI inflation. These results are prima facie consistent with other recent studies that have attempted to identify a role for the exchange rate in reaction functions, but more work needs to be done to assess whether or not this result is robust under alternative assumptions about the structure of the economy and the form of the loss function that is used to evaluate alternative monetary policy rules.

\section{Conclusion}

We have found that rules that perform well in models of the US economy also perform well in our simulation model of a relatively closed economy. But some of these rules - such as the original Taylor (1993) rule and the simple LWW rule - may be inefficient when they are applied to small open economies because they respond too weakly to forecasts of inflation and too strongly to movements in the output gap. However, we have shown that a simple modified LWW rule that responds more strongly to the forecast of inflation may produce better macroeconomic performance in small, open, emerging economies.

A number of extensions and refinements are left to future research. First, it may be worthwhile to study the implications of alternative measures of the output gap based on a flexible-price measure of potential output. Second, to be consistent with the historical 
data, our model was calibrated to account for high degrees of structural persistence in the inflation process. However, as argued by Erceg and Levin (2001), estimates of inflation persistence based on historical data, which cover periods of large disinflations, may overestimate the degree of structural inflation persistence, as the observed inflation inertia may stem partly from a slow adaptation of expectations to the shift from a high to a low inflation regime. Therefore, further sensitivity analysis should consider this issue explicitly by studying alternative calibrations with significantly lower structural inflation persistence.

Finally, the development of perturbation methods has progressed sufficiently that formal welfare analysis on the non-linear version of the model, regardless of its analytical complexity, may soon become feasible. Looking forward to these developments, this study may provide a useful benchmark to compare differences between formal welfare analysis, based on the non-linear version of the model, and the more conventional analysis presented here, based on a simple loss function and the linearized version of the model. 


\section{References}

[1] Armstrong, J., Black, D., Laxton, D., Rose, D., 1998. A robust method for simulating forward-looking models. Journal of Economic Dynamics and Control 22, 489-501.

[2] Bacchetta, P., and Van Wincoop, E. 2000. Does exchange-rate stability increase trade and welfare? American Economic Review 90 (5), 1093-1109.

[3] Balassa, B.,1964. The purchasing power doctrine: a reappraisal. Journal of Political Economy 72, 584-596.

[4] Batini, N., Harrison, R., Millard, S., 2001. Monetary policy rules for an open economy. Bank of England Working Paper 149.

[5] Benigno, G., Benigno, P., 2003. Price stability in open economies. Review of Economic Studies, forthcoming.

[6] Benigno, G., and Thoenissen, C., 2002. Equilibrium exchange rates and UK supply side performance. Bank of England Working Paper.

[7] Benigno, P., 2001. Price stability with imperfect financial integration. New York University Working Paper.

[8] Black, R., Macklem, T., Rose, D., 1997. On policy rules for price stability, in: Price Stability, Inflation Targets and Monetary Policy, proceedings of a conference at the Bank of Canada (Ottawa), 411-461.

[9] Burstein, A.T., Neves, J.C., Rebelo, S., 2003. Distribution costs and real exchange rate dynamics during exchange rate based stabilizations. Journal of Monetary Economics, forthcoming.

[10] Campa, J., and L. Goldberg, 2002. Exchange rate pass-through into import prices. Working Paper, IESE Business School and Federal Reserve Bank of New York, December. 
[11] Chari, V., Kehoe, P., McGrattan, E., 2002. Can sticky price models generate volatile and persistent real exchange rates? Review of Economic Studies 69, 533-63.

[12] Christiano, L., M. Eichenbaum, C. Evans, 1999. Monetary Policy Shocks: What Have we Learned and to What End?, in Taylor, J., Woodford, M., eds., Handbook of Macroeconomics, Vol. 1A (North Holland: Amsterdam) 65-148.

[13] Corsetti, G., Dedola L., 2002. Macroeconomics of international price discrimination, Working Paper, University of Rome III and Bank of Italy.

[14] Corsetti, G., Pesenti, P., 2001a. International dimensions of optimal monetary policy. National Bureau of Economic Research Working Paper 8230.

[15] Corsetti, G., Pesenti, P., 2001b. Welfare and macroeconomic interdependence. Quarterly Journal of Economics 116 (2), 421-446.

[16] Devereux, M., Engel, C., 2000. Monetary policy in the open economy revisited: price setting and exchange rate flexibility. National Bureau of Economic Research Working Paper 7665 .

[17] Domowitz, I., Hubbard, G., Petersen, B., 1988. Market structure and cyclical fluctuations in U.S. manufacturing. Review of Economics and Statistics 80, 55-66.

[18] Erceg, C., Guerrieri, L., and Gust, C., 2002. Productivity growth and the trade balance in the 1990s: the role of evolving perceptions. Board of Governors of the Federal Reserve System Working Paper.

[19] Erceg, C., Levin, A., 1996. Structures and the dynamic behavior of the real exchange rate. Board of Governors of the Federal Reserve System, International Finance Discussion Paper 554 
[20] Erceg, C., Levin, A., 2001. Imperfect credibility and inflation persistence. Board of Governors of the Federal Reserve System Finance and Economics Discussion Series $2001-45$.

[21] Fagan, G., Henry, J.,Mestre, R., 2001. An area-wide model (AWM) for the Euro Area. European Central Bank Working Paper 42.

[22] Galí, J., Gertler, M., and López-Salido, J., 2002. Markups, gaps, and the welfare costs of business fluctuations. National Bureau of Economic Research Working Paper 8850.

[23] Galí, J., and T. Monacelli, 2002. Monetary policy and exchange rate volatility in a small open economy. National Bureau of Economic Research Working Paper 8905.

[24] Ghironi, F., Rebucci, A., 2002. Monetary rules for emerging market economies. International Monetary Fund Working Paper 02/34.

[25] Halpern, L., Wyplosz, C., 2001. Economic transformation and real exchange rates in the 2000s: The Balassa-Samuelson connection, in: Economic Survey of Europe 2001, No. 1 (Geneva, United Nations Economic Commission for Europe), Chapter 6, 227-239.

[26] Hooper, P., Marquez, J., 1995. Exchange rates, prices, and external adjustment in the United States and Japan, in: P. Kenen, ed., Understanding Interdependence (Princeton, NJ: Princeton University Press), 107-168.

[27] Ireland, P., 2001. Sticky-price models of the business cycle: specification and stability. Journal of Monetary Economics 47 (1), 3-18.

[28] Isard, P., Laxton, D., Eliasson, A., 1999. Simple monetary policy rules under model uncertainty, in: Isard, P., Razin, A., Rose, A., eds., International Finance and Financial Crises: Essays in Honor of Robert P. Flood Jr., (Washington: International Monetary Fund and Boston: Kluwer). 
[29] Isard, P., Laxton, D., 2001. Inflation targeting with NAIRU uncertainty and endogenous policy credibility. Journal of Economic Dynamics \& Control 21, 115-48.

[30] Juillard, M , Laxton, D., Pioro, H., McAdam, P., 1998. An algorithm competition: First order iterations versus Newton-based techniques. Journal of Economic Dynamics and Control 22, 1291-1318.

[31] Juillard, M and D. Laxton, 2003. The IMF's Global Economy Model: The Collection of DYNARE Programs Used for Model Solution and Analysis. Working Paper, International Monetary Fund, forthcoming.

[32] Kim, J., 2000. Constructing and estimating a realistic optimizing model of monetary policy. Journal of Monetary Economics 45 (2), 329-359.

[33] Kollmann, R., 2001. Macroeconomic effects of nominal exchange rate regimes: new insights into the role of price dynamics. University of Bonn Working Paper.

[34] Laxton, D., Rose, D., Tetlow, R., 1993. Monetary policy, uncertainty and the presumption of linearity. Bank of Canada Technical Report 63.

[35] Levin, A., Wieland, V., Williams, J., 2001. The performance of forecast-based monetary policy rules under model uncertainty. Board of Governors of the Federal Reserve, Finance and Economics Discussion Series 2001-39.

[36] Lipschitz, L., Lane, T., Mourmouras, A., 2002. Capital flows to transition economies: Master or servant? International Monetary Fund Working Paper 02/11.

[37] Martins, J., Scarpetta, S., Pilat, D., 1996. Mark-up pricing, market structure and the business cycle. OECD Economic Studies 27 (II), 71-106.

[38] McCallum, B., Nelson, E., 1999. Nominal income targeting in an open-economy optimizing model. Journal of Monetary Economics 43 (3), 553-578. 
[39] McCallum, B., 2002. Multiple solution indeterminacies in monetary policy analysis. Carnegie-Rochester Conference Series on Public Policy, November.

[40] Morrison, C., 1994. The cyclical nature of markups in Canadian manufacturing: A production theory approach. Journal of Applied Econometrics 9 (3), 269-282.

[41] Natalucci, F.M., Ravenna, F., 2002. The road to adopting the Euro: monetary policy and exchange rate regimes in EU candidate countries. Board of Governors of the Federal Reserve System Working Paper 2002-741.

[42] Obstfeld, M., Rogoff, K., 1995. Exchange rate dynamics redux. Journal of Political Economy 103, 624-660.

[43] Obstfeld, M., Rogoff, K., 1996. Foundations of International Macroeconomics (Cambridge, MA: MIT Press).

[44] Obstfeld, M., Rogoff, K., 2000. New directions for stochastic open economy models. Journal of International Economics 50 (1), 117-153.

[45] Pesenti, P., 2003. The Global Economy Model (GEM): Theoretical framework. International Monetary Fund Working Paper, forthcoming.

[46] Rotemberg, J., 1982. Sticky prices in the United States. Journal of Political Economy 90, 1187-1211.

[47] Rotemberg, J., Woodford, M., 1998. An optimization-based econometric framework for the evaluation of monetary policy: Expanded version. National Bureau of Economic Research Technical Working Paper t0233.

[48] Samuelson, P., 1964, Theoretical notes on trade problems. Review of Economics and Statistics 46, 145-154.

[49] Schmitt-Grohe, S., Uribe, M., 2003. Optimal fiscal and monetary policy under sticky prices. Journal of Economic Theory, forthcoming. 
[50] Smets, F., Wouters, R., 2002a. Openness, imperfect exchange rate pass-through and monetary policy, Journal of Monetary Economics 49, 947-81.

[51] Smets, F., Wouters, R., 2002b. An estimated stochastic dynamic general equilibrium model of the euro area. ECB Working Paper 171.

[52] Svensson, L., 2003. What is wrong with Taylor rules? Using judgement in monetary policy through targeting rules. Journal of Economic Literature, forthcoming.

[53] Svensson, L., Woodford, M., 2003. Implementing optimal policy through inflationforecast targeting. Princeton University Working Paper.

[54] Taylor, J., 1993. Discretion versus policy rules in practice. Carnegie-Rochester Conference Series on Public Policy 39, 195-214.

[55] Taylor, J., 2000. Using monetary policy rules in emerging economies, in: Stabilization and Monetary Policy: The International Experience (Mexico City: Bank of Mexico), 441-458.

[56] Tille, C., 2001. The role of consumption substitutability in the international transmission of monetary shocks. Journal of International Economics 53(2), 421-444.

[57] Woodford, M., 1999. Optimal monetary policy inertia. National Bureau of Economic Research Working Paper 7261.

[58] Woodford, M., 2002. Price-level determination under interest-rate rules, in: Woodford, M., Interest and Prices, Chapter 2 (Princeton University Press), forthcoming. 
Table 1

Measures of Macro Variability of the Euro Area and Czech Republic

\begin{tabular}{|c|c|c|c|c|}
\hline & \multicolumn{2}{|c|}{ Euro Area } & \multicolumn{2}{|c|}{ Czech Republic } \\
\hline & $\begin{array}{c}\text { Historical } \\
\text { (1970Q1-2000Q4) }\end{array}$ & Model & $\begin{array}{c}\text { Historical } \\
\text { (1993Q1-2001Q4) }\end{array}$ & Model \\
\hline Standard deviation (in \%) & & & & \\
\hline Real GDP & 1.0 & 1.1 & 2.0 & 2.0 \\
\hline Consumption & 0.8 & 1.2 & 2.2 & 2.8 \\
\hline Investment & 2.7 & 2.6 & 7.3 & 7.9 \\
\hline Government Expenditure & 0.6 & 0.7 & 2.6 & 2.6 \\
\hline Exports & 2.4 & $\ldots$ & 3.9 & 4.1 \\
\hline Imports & 3.1 & $\ldots$ & 4.1 & 3.5 \\
\hline Net Exports (\% of GDP) & 0.6 & $\ldots$ & 1.6 & 2.0 \\
\hline CPI Inflation (y-o-y) & 3.7 & 0.7 & 5.3 & 1.5 \\
\hline Short-Term Interest Rate & 2.9 & 1.1 & 4.1 & 2.0 \\
\hline Real Effective Exchange Rate & $\ldots$ & $\ldots$ & 3.1 & 5.4 \\
\hline
\end{tabular}


Table 2

Assumptions About the Shocks 1/

\begin{tabular}{lcccc} 
& \multicolumn{2}{c}{ Standard Error } & \multicolumn{2}{c}{ Persistence Parameter } \\
& Home & Foreign & Home & Foreign \\
\hline Risk Premium & 0.0170 & & 0.70 & \\
Productivity (LOG) & 0.0020 & 0.0001 & 0.95 & 0.95 \\
Investment Depreciation Rate & 0.0700 & 0.0050 & 0.95 & 0.95 \\
Marginal Utility of Consumption (LOG) & 0.0040 & 0.0010 & 0.70 & 0.70 \\
Government Absorption/GDP & 0.0035 & 0.0008 & 0.95 & 0.95 \\
Marginal Disutility of Labor (LOG) & 0.1000 & 0.0100 & 0.95 & 0.95 \\
Preference Shifter (LOG) & 0.0200 & 0.0180 & 0.95 & 0.95 \\
\hline 1/ Each variable is assumed to follow a stochastic process $y_{t}=(1-\Psi) \bar{y}_{t}+\Psi y_{t-1}+\varepsilon_{t}^{y}$, \\
where y is either the variable or the log of the variable, $\bar{y}$ is the steady-state value, $\Psi$ is a \\
persistence parameter, and $\varepsilon_{t}{ }^{y}$ is a Gaussian disturbance term.
\end{tabular}


Table 3

A Comparison of GEM's Monetary Transmission Mechanism with the ECB's Area Wide Model (AWM) (Responses to 100 Basis Point Interest Rate Hike)

\begin{tabular}{|c|c|c|c|c|c|c|c|c|}
\hline \multicolumn{9}{|l|}{ Real GDP } \\
\hline AWM & -0.1 & -0.2 & -0.2 & -0.3 & -0.3 & -0.3 & -0.3 & -0.3 \\
\hline \multicolumn{9}{|c|}{ Domestic Absorption } \\
\hline GEM Foreign & -0.2 & -0.3 & -0.4 & -0.4 & -0.4 & -0.3 & -0.2 & -0.2 \\
\hline GEM Foreign & -0.1 & -0.2 & -0.3 & -0.3 & -0.3 & -0.2 & -0.2 & -0.2 \\
\hline AWM & -0.0 & -0.2 & -0.2 & -0.3 & -0.4 & -0.3 & -0.3 & -0.3 \\
\hline \multicolumn{9}{|l|}{ Investment } \\
\hline GEM Foreign & -0.6 & -0.9 & -1.1 & -1.1 & -1.0 & -0.8 & -0.6 & -0.4 \\
\hline AWM & -0.1 & -0.5 & -0.8 & -1.2 & -1.5 & -1.4 & -1.3 & -1.2 \\
\hline \multicolumn{9}{|l|}{ Exports } \\
\hline AWM & -0.2 & -0.5 & -0.7 & -0.9 & -0.9 & -0.7 & -0.6 & -0.6 \\
\hline \multicolumn{9}{|l|}{ Exchange Rate } \\
\hline GEM Foreign & 0.9 & 0.7 & 0.5 & 0.3 & 0.1 & 0.1 & 0.1 & 0.1 \\
\hline AWM & 0.5 & 0.3 & 0.0 & -0.2 & -0.5 & -0.4 & -0.4 & -0.3 \\
\hline \multicolumn{9}{|l|}{ CPI } \\
\hline GEM Foreign & -0.0 & -0.0 & -0.1 & -0.1 & -0.1 & -0.2 & -0.2 & -0.2 \\
\hline AWM & -0.0 & -0.0 & -0.0 & -0.0 & -0.1 & -0.1 & -0.1 & -0.1 \\
\hline
\end{tabular}


Table 4. Optimal Calibrations of Generalized Taylor Rules fo the Home Country

\begin{tabular}{lccccccccc}
\hline & \multicolumn{3}{c}{ Loss Function 1/ } & \multicolumn{4}{c}{ Optimal Weights 2/ } & \multicolumn{3}{c}{ Measures of Macro Variability } \\
\cline { 2 - 9 } & $\Lambda_{\text {ygap }}$ & $\Lambda_{i}$ & $\Lambda$ & $\omega_{i}$ & $\omega_{1}$ & $\omega_{2}$ & $\sigma_{\left(P_{t} / P_{t-4}\right)}$ & $\sigma_{y g a p}$ & $\sigma_{\Delta i}$ \\
\hline 1 & 0.50 & 0.50 & 4.98 & 0.91 & 0.42 & 0.13 & 1.63 & 1.99 & 0.83 \\
2 & 1.00 & 0.50 & 6.88 & 0.92 & 0.40 & 0.18 & 1.70 & 1.92 & 0.79 \\
3 & 1.50 & 0.50 & 8.68 & 0.92 & 0.39 & 0.22 & 1.77 & 1.87 & 0.78 \\
4 & 2.00 & 0.50 & 10.40 & 0.93 & 0.39 & 0.26 & 1.84 & 1.83 & 0.77 \\
\hline
\end{tabular}


Table 5. Optimal Calibrations of Inflation-Forecast-Based Rules for the Home Country

\begin{tabular}{cccccccccc}
\hline & \multicolumn{3}{c}{ Loss Function 1/ } & \multicolumn{3}{c}{ Optimal Weights 2/ } & \multicolumn{3}{c}{ Measures of Macro Variability } \\
& $\Lambda_{\text {ygap }}$ & $\Lambda_{i}$ & $\Lambda$ & $\omega_{i}$ & $\omega_{1}$ & $\omega_{2}$ & $\sigma_{\left(P_{t} / P_{t-4}\right)}$ & $\sigma_{y g a p}$ & $\sigma_{\Delta i}$ \\
\hline 1 & 0.50 & 0.50 & 4.97 & 1.00 & 1.78 & 0.23 & 1.78 & 1.74 & 0.76 \\
2 & 1.00 & 0.50 & 6.47 & 1.00 & 1.87 & 0.34 & 1.78 & 1.73 & 0.80 \\
3 & 1.50 & 0.50 & 7.95 & 1.00 & 1.91 & 0.44 & 1.79 & 1.71 & 0.82 \\
4 & 2.00 & 0.50 & 9.41 & 1.00 & 1.92 & 0.55 & 1.81 & 1.70 & 0.84 \\
\hline
\end{tabular}

$1 /$ Loss function is $\Lambda=\sigma^{2}\left(P_{t} / P_{t-4}\right)+\Lambda_{y g a p} \sigma^{2}(y g a p)+\Lambda_{i} \sigma^{2}\left(i_{t+1}-i_{t}\right)$

$2 /$ Reaction function is

$\left(1+i_{t+1}\right)^{4}-1=\omega_{i}\left[\left(1+i_{t}\right)^{4}-1\right]+\left(1-\omega_{i}\right)\left[\left(1 / \beta^{4}\right)\left(P_{t} / P_{t-4}\right)-1\right]+\omega_{1}\left[P_{t} / P_{t-4}-\Pi_{t}\right]+\omega_{2}\left[\right.$ ygap $\left.p_{t}\right]$ 


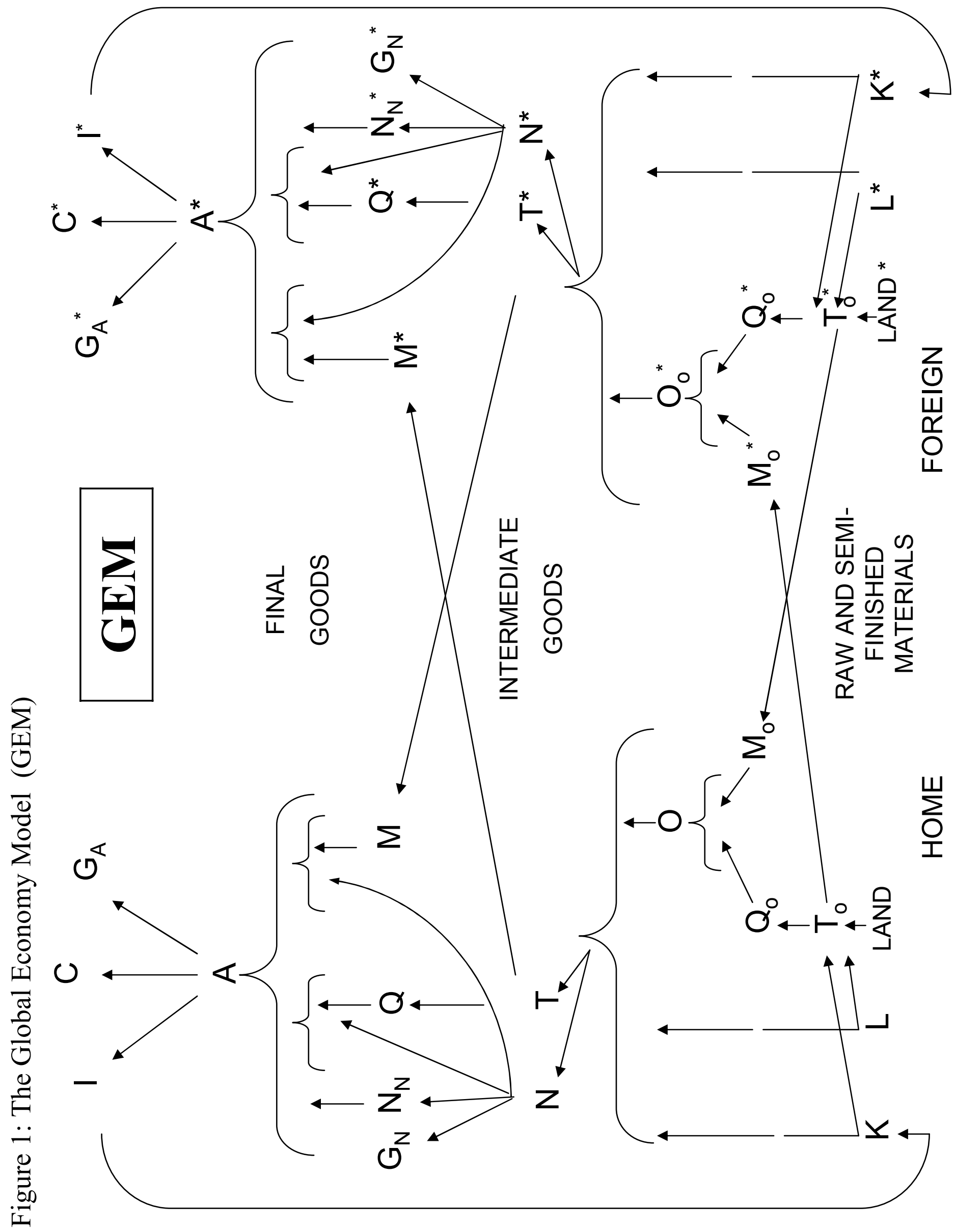


Figure 2: Foreign Country: Permanent One Percentage Point Disinflation Shock

(Deviation from control; In percent)

- Home $\quad--$ Foreign

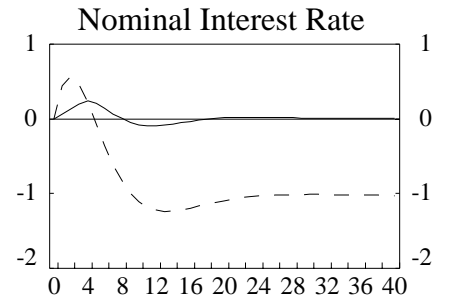

Real Exchange Rate (Based on CPI)
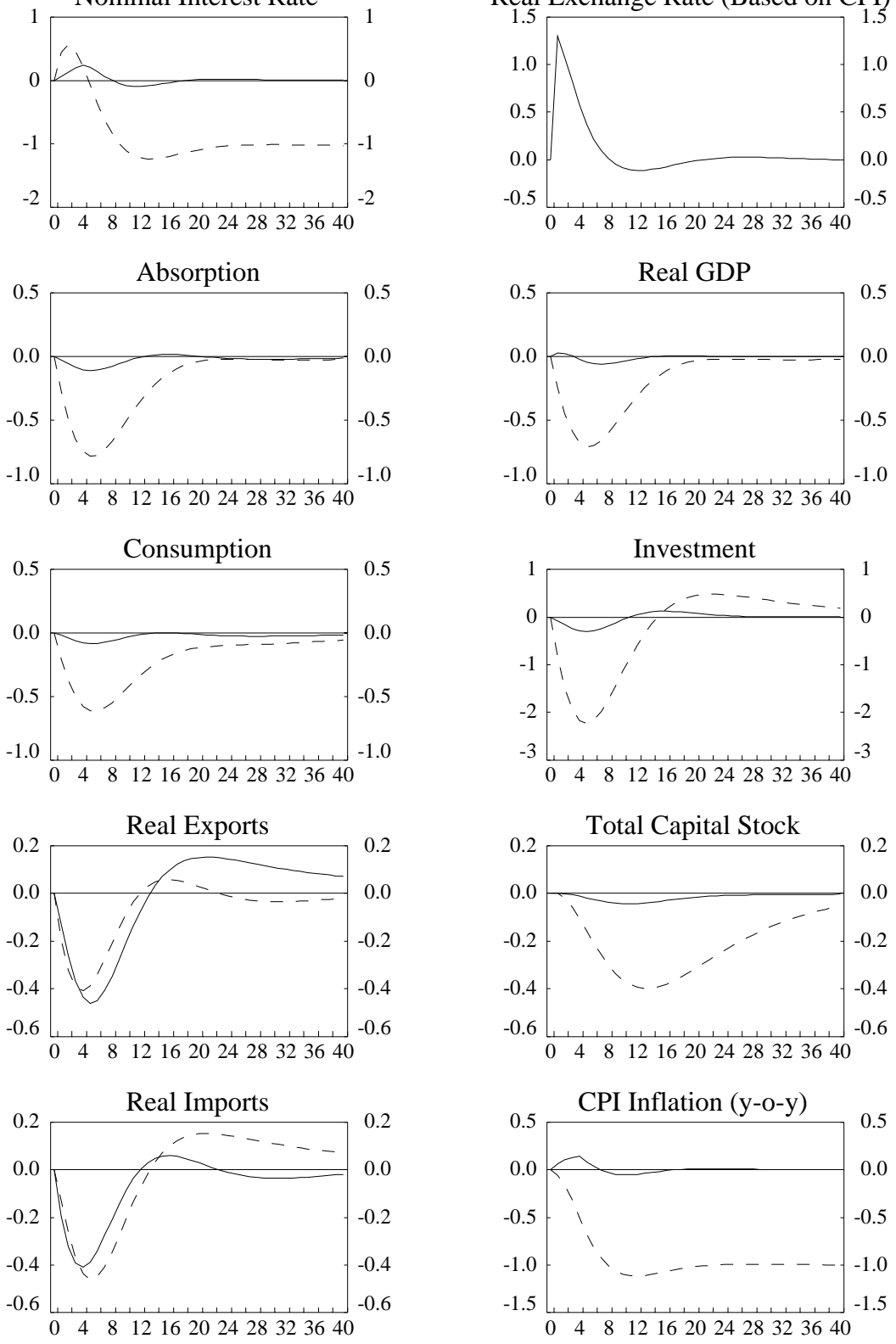
Figure 3. A Comparison of a Disinflation Shock in the Home Country of GEM and in the Czech National Bank's Quarterly Projection Model

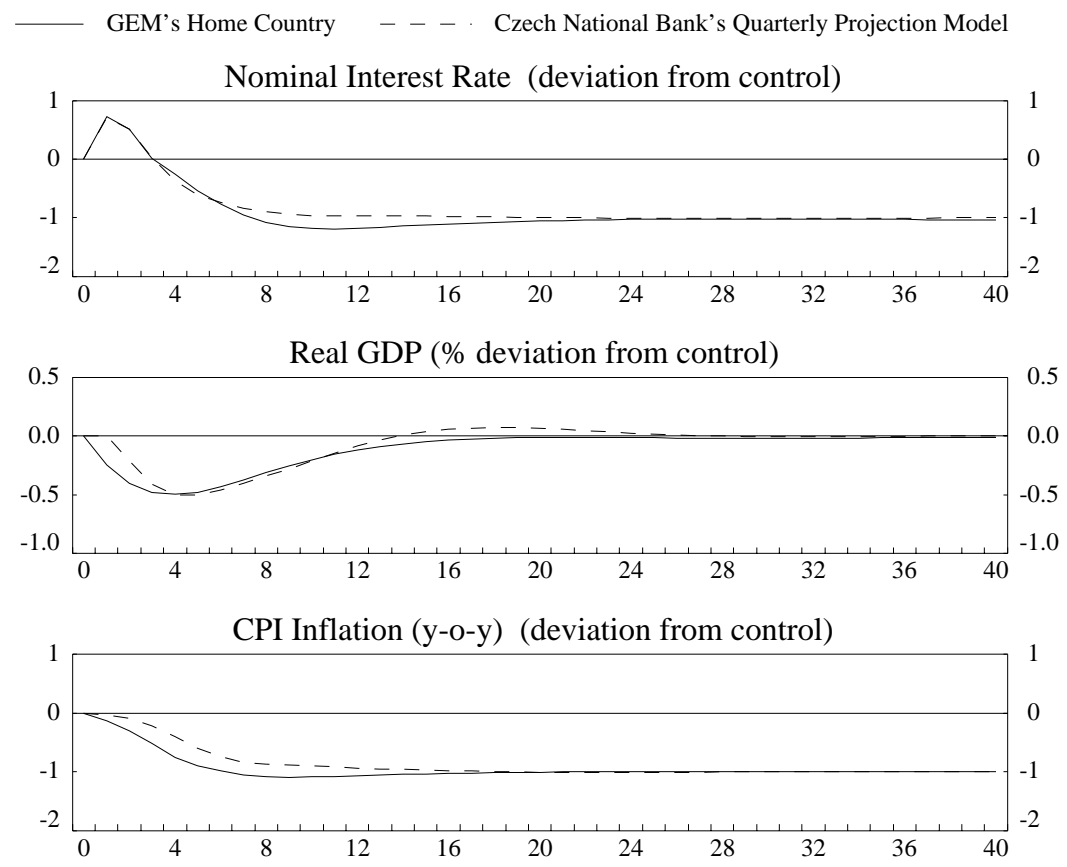


Figure 4: A Comparison of the Taylor-Rule Based Output-Inflation Efficiency Frontiers for the Home Country and the Foreign Country

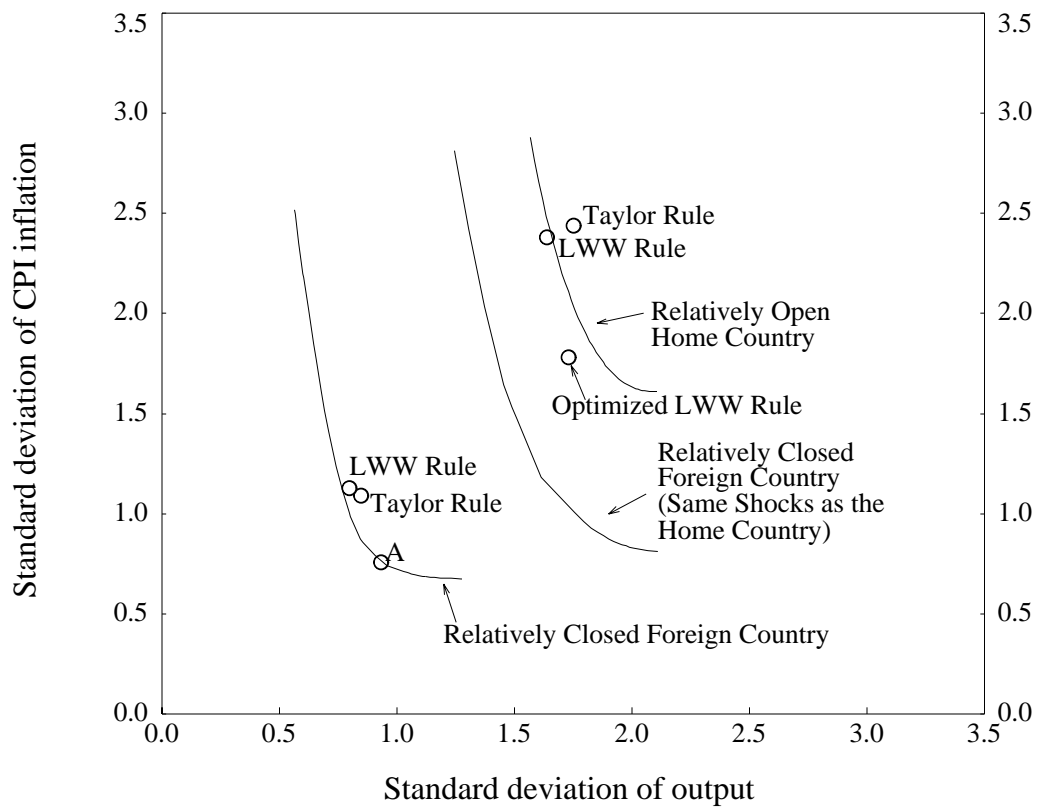

